Article

\title{
Determining the cytotoxic properties and mechanisms against drug resistance of an aqueous extract of Fagonia indica on colon cancer cells
}

\author{
Amber Lewis ${ }^{1}$, Catherine Shelton ${ }^{1}$, Weiguang Wang ${ }^{2,3}$, Vinodh Kannappan ${ }^{2,3}$, Amtul R. \\ Carmichael $^{1,4}$, Alice Rothnie ${ }^{1}$ and James E. Brown ${ }^{1 *}$ \\ 1 School of Biosciences, College of Health and Life Sciences, Aston University, Aston \\ Street, Birmingham, B4 7ET, UK. \\ 2 Faculty of Science \& Engineering, University of Wolverhampton, Wolverhampton WV1 \\ 1LY, UK \\ ${ }^{3}$ Disulfican Ltd, UK \\ ${ }^{4}$ University Hospital of Derby and Burton NHS Foundation Trust, Queens Hospital, \\ Belverdere Road, Burton upon Trent, DE13 0RB, UK. \\ * Correspondence: J.E.P.Brown@aston.ac.uk
}

\begin{abstract}
Fagonia indica is a perennial plant grown in arid climates and utilised in traditional medicine as a treatment for cancer. Previous research has highlighted potential antineoplastic effects of Fagonia indica against breast cancer cell lines. Despite this, there has been little research demonstrating the potential of an aqueous extract of Fagonia indica against colon cancer. Colon cancer is a leading cause of cancer-related mortality, with drug resistance remaining a barrier to treatment. The aim of the present study was to investigate the cytotoxic mechanisms of Fagonia indica in colon cancer cells, including pathways related to proliferation, angiogenesis and inflammation and ABC membrane transporters. Treatment with Fagonia indica caused a reduction in wild-type and chemotherapy resistant colon cancer. Results indicated a role for Akt/MAPK signalling as a mechanism of Fagonia indica induced cell death, alongside a reduction in the expression of VEG-F, NK- $\kappa B$ and ICAM-1. RT-PCR demonstrated a reduction in expression of ABCG2/ABCC4 in resistant colon cancers. Further research is required to isolate bioactive compounds of Fagonia indica for use against colon cancer.
\end{abstract}

Keywords: Fagonia indica, colon cancer, proliferation, angiogenesis, ABCC4, ABCG2

\section{Introduction}

Colon cancer is one of the most frequently diagnosed cancers and a leading cause of cancer related mortality in both males and females [1-2]. Although survival rates of colon cancer are increasing in many high-income countries, there has been an increase in incidence among a younger population of $1.4 \%$ per year [3]. Previous studies have identified several potential risk factors for colon cancer including, BMI, Westernised diets, abnormal bowel frequency and aspirin use [4-6]. Long-term inflammatory bowel diseases; such as Crohn's and ulcerative colitis, are also a strong risk factor for bowel cancers [7]. Colon cancer is becoming increasingly prevalent in low-income countries with rapidly Westernising lifestyles, despite significant improvements in screening programmes and treatment options [8]. 
Current therapeutic interventions for colon cancer include a surgical resection and combination chemotherapy, including 5-fluorouracil (5-FU) and oxaliplatin [9]. Alarmingly, drug resistance to single chemotherapy agents occurs almost universally, with resistance developing as a selection pressure via DNA mutation and metabolic alterations [10-12]. The ATP-binding cassette transporters (ABCA-ABCG) are a superfamily of efflux proteins, which transport structurally diverse substances across the cell membrane, against the concentration gradient [13-14]. The ability of transmembrane proteins to mediate transport of chemotherapeutic compounds and their metabolites has since been linked to aberrant expression of one, or many of these $\mathrm{ABC}$ transporters in multidrug resistant cancers (MDR) [15-17]. Studies have shown that exposure with low-dose chemotherapeutic agents for 10 days was sufficient to upregulate AGCG2 in relation to multidrug resistance phenotypes in colon cancer [18-19]. In combination therapies for colon cancer, additional compounds can confer resistance to 5-FU and oxaliplatin via the upregulation $\mathrm{ABC}$ transporters including $\mathrm{ABCC} 4$ [20]. Inhibiting the expression of $A B C$ transporters in cell lines expressing resistance, can result in a reversal of the resistant phenotype. For example, inhibition of ABCC4 in acute myeloid leukaemia enhanced the accumulation of intracellular drug concentration by $150 \%$ [17]. Inhibiting ABCC4 in colon cancer cell lines resulted in a significant increase in intracellular accumulation and sensitivity of treatment with 5-FU [21]. Therefore, inhibition or downregulation of $\mathrm{ABC}$ transporters is vital in reversing multidrug resistance, enhance accumulation of intracellular drug concentration and reduce the likelihood of metastasis [2122].

The vascular endothelial growth factor (VEGF) family have an increasingly established role as angiogenic activators and propagators of inflammation in colon cancer. VEGF-A plays a central role in endothelial cell proliferation, invasion, migration and survival of primary tumors via its interaction with the vascular endothelial growth factor receptor -2 (VEGFR-2) [23]. Overexpression of VEGF-A has been identified in several studies of human colon cancer and is correlated with an increased risk of invasion and metastasis. VEGF has been shown to directly regulate the expression of ICAM-1 (intracellular adhesion-molecule 1) via the phosphatidylinositol $3 \mathrm{OH}$-kinase (PI3K)/AKT pathway in brain microvascular endothelial cells [24]. Aberrant expression of both VEGF and ICAM-1 has been used to predict clinical outcome of patients with metastatic colon cancer, with a positive correlation between protein expression of VEGF and ICAM-1 in tissue from biopsied colon cancers compared with healthy controls [25]. The tendency of this relationship was significantly higher in tumors of increased size or with metastasis [26]. There has also been a strong correlation between VEGF-associated angiogenesis and the propagation of inflammatory states. Studies have demonstrated the capacity of VEGF to induce a pro-inflammatory phenotype via the induced expression of ICAM-1 and VCAM-1 in inflammatory bowel disease (IBD), [27]. The mechanism behind the induction of VEGF as a pro-inflammatory cytokine has been in part attributed to stimulation from the nuclear factor NF-kB signaling pathway.

Fagonia indica is a small, spiny undershrub belonging to the family Zygophyllaceae, found largely in warm arid regions of most continents [28-30]. Indigenous use of Fagonia indica varies greatly between individual communities [31-36]. Typically, the aerial section of the shade-dried plant is ground into a powder and administered orally as an aqueous tea [33]. Treatment of experimentally produced subcutaneous tumors in albino rats with Fagonia indica extract, resulted in a significant increase in overall survival of both male and females [37]. Cytotoxic 
properties have also been demonstrated in in vitro studies on breast (MCF-7) and colon (HCT) cancer cell lines [38]. Further research found that MCF-7 and MDA-MB-231 cells were more susceptible to cell cycle modulation, double strand DNA damage and activation of p53, p21 and downstream signaling targets upon treatment with Fagonia indica [39]. Interestingly, loss of cell viability was also attributed; in part, to p53 independent FOXO3a activation. FOXO3 has numerous modes of action, including regulation of apoptosis, DNA damage responses and cell cycle arrest [40]. Despite this, there is little understanding regarding the mechanism of Fagonia indica extract induced apoptosis in colon cancer. In the current study, the effect of Fagonia indica is determined on two p53 positive colon cancer cell lines, in order to expand on the pathways described in previous work [39]. There has been no prior research regarding the effect of Fagonia indica extract on pathways related to tumour growth and propagation, such as angiogenesis and inflammation. This study investigated the potential for Fagonia indica extract to inhibit the growth of colon cancer cells in vitro and inhibit pathways related to tumour growth and apoptosis. For the first time, the effect of Fagonia indica against chemotherapy resistant colon cancer cell lines was investigated, with a particular interest in the relationship between extract treatment and ABC transporters, ABCC4 and ABCG2.

\section{Results}

2.1 An aqueous extract of Fagonia indica decreases cell viability and intracellular ATP in colon cancer cells.

In order to determine whether an aqueous extract of Fagonia indica was cytotoxic against in vitro colon cancer cells; RKO and H630, cell viability and intracellular ATP levels were determined as shown in Figure 1. Extract treatment in the concentration range $0-2.5 \mathrm{mg} / \mathrm{mL}$ over 72 hours induced a significant time- and concentration-dependent reduction in cell viability (Figure 1A-B). After 72 hours, $2.5 \mathrm{mg} / \mathrm{mL}$ of extract treatment caused a $62 \%$ and $64 \%$ reduction in cell viability in RKO and $\mathrm{H} 630$ cell lines, respectively. Altered metabolism is a key feature of tumorigenesis, and high intracellular ATP levels are synonymous with tumour development. Intracellular ATP levels were measured in in vitro colon cancer cell lines (Figure 1C-D). Extract treatment at $1 \mathrm{mg} / \mathrm{mL}$ over 24 hours induced a significant reduction in both RKO and H630 intracellular ATP levels by $70.3 \%$ and $68.3 \%$, respectively. 
(A)

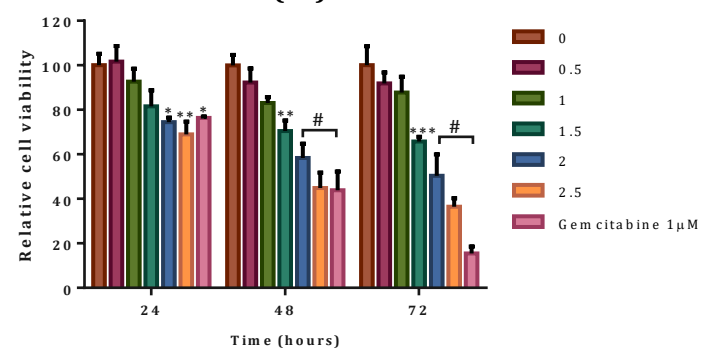

(C)

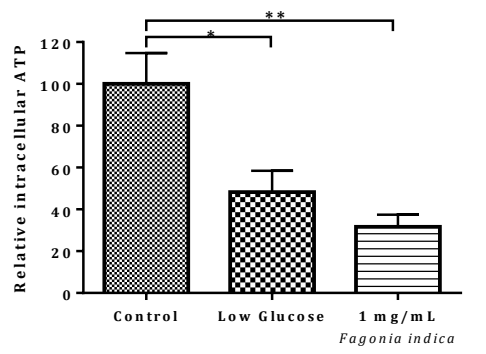

(B)

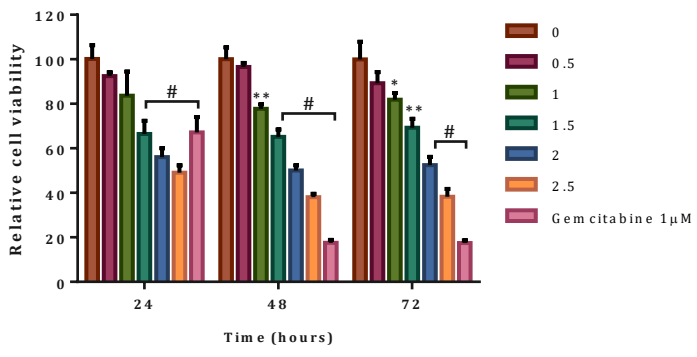

(D)

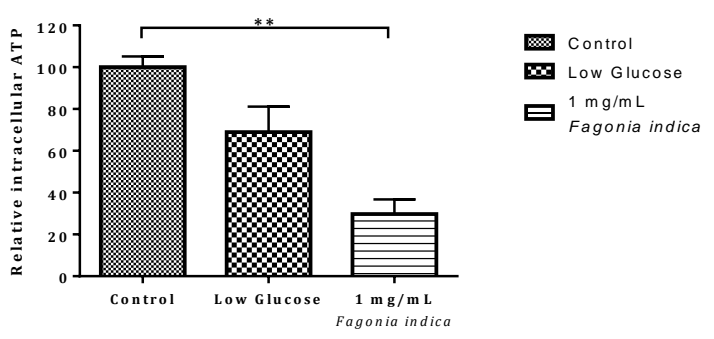

Figure 1. Fagonia indica extract treatment reduces in vitro cell viability and intracellular ATP of $\mathrm{H} 630$ and RKO colon cancer cell lines. (A) H630 and (B) RKO cells were treated with $0-2.5 \mathrm{mg} / \mathrm{mL}$ aqueous Fagonia indica extract or $1 \mu \mathrm{M}$ of Gemcitabine, as a positive control for 24-72 hours. Cell viability was determined as a percentage of an untreated DMSO vehicle control using the NR assay. (C) H630 and (D) RKO were treated with $1 \mathrm{mg} / \mathrm{mL}$ aqueous Fagonia indica extract or low glucose supplemented DMEM for 24 hours prior to analysis of intracellular ATP with a luminescent assay. ATP concentration was determined as a percentage of an untreated control Data denoted * $(\mathrm{p}<0.05),{ }^{* *}(\mathrm{p}<0.01),{ }^{* * *}(\mathrm{p}<0.001)$ and \# $(\mathrm{p}<0.0001)$ were significantly different compared to the untreated control analysed by one-way (C-D) and two-way (A-B) ANOVA with Dunnett's multiple comparison test. All data is representative of at least three independent experiments performed in triplicate and presented as mean \pm SEM 


\subsection{Fagonia indica treatment reduces proliferation and migration of colon cancer cells.}

Having established that an aqueous extract of Fagonia indica was able to significantly reduce cell viability, the effect of the extract on the ability of cells to proliferate and migrate was investigated. A colony formation assay was used to determine the ability of cells to reproduce from a single cell. Pre-treatment of H630 and RKO cells with Fagonia indica for 24 hours caused a significant reduction in colony formation from a single cell after 7 days (Figure 2). In H630 cells, pretreatment with Fagonia indica for 24 hours, reduced colony formation after 7 days by $29.6 \%$ (Figure 2B). For RKO cells there was a significant reduction in colony formation by $29.5 \%$ (Figure 2D). Alongside increased proliferation, enhanced migration is a phenotype of cancer and is a key indicator of potential for metastasis. The scratch wound assay is a well-developed method to analyse cell migration in vitro. Treatment with Fagonia indica extract $(1 \mathrm{mg} / \mathrm{mL})$ did not significantly reduce wound closure of either H630 (Figure 3A-B) or RKO (Figure 3C-D) cells after 24 hours.

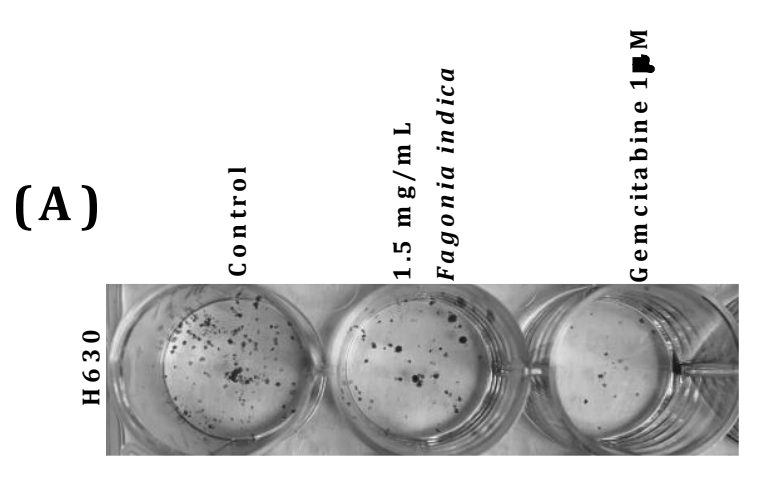

(B)

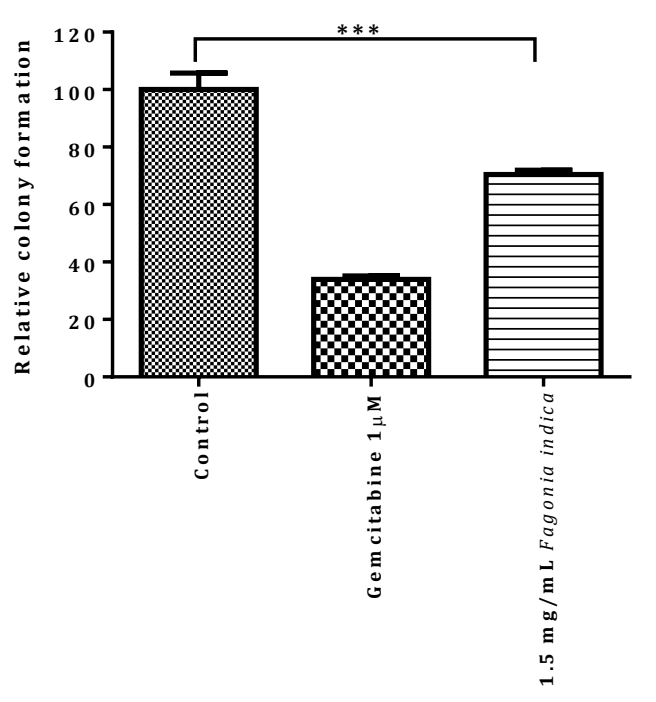

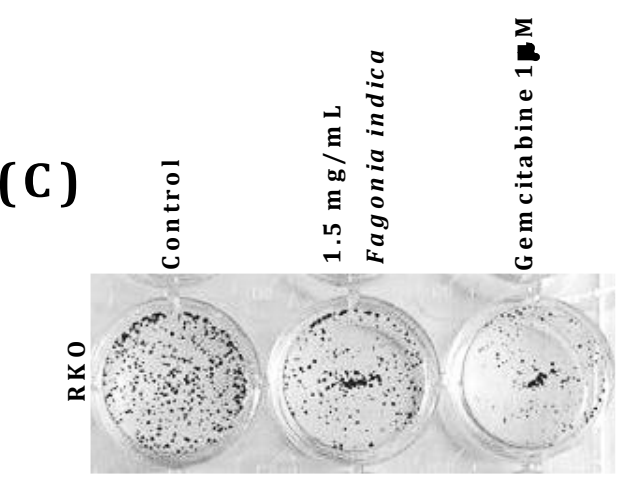

(D)

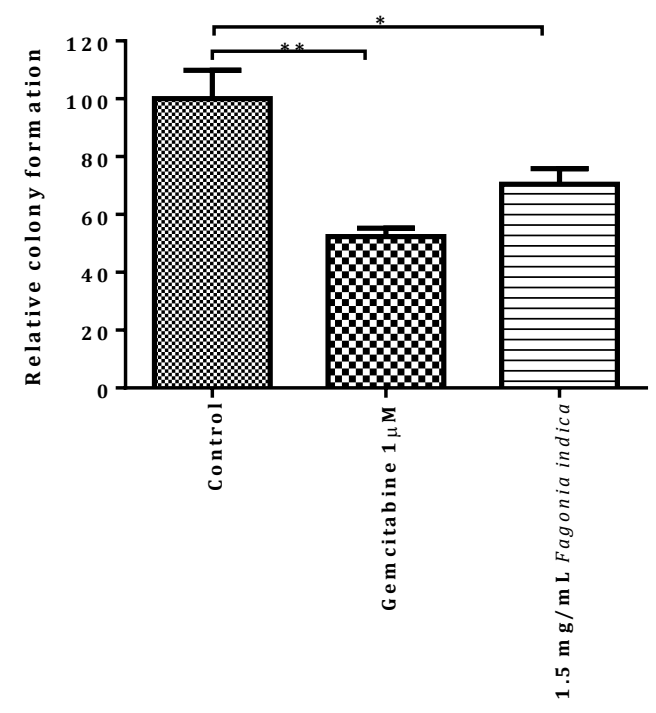

Figure 2: Fagonia indica treatment inhibits proliferation of colon cancer cell lines. (A-B) H630 cells were seeded at a density of 200 cells per well and (C-D) RKO cells were seeded at 400 cells per well in a 24 well plate, after pre-treatment 
with $1.5 \mathrm{mg} / \mathrm{mL}$ aqueous Fagonia indica or $1 \mu \mathrm{M}$ Gemcitabine, as a positive control for 24 hours. After 1 week, colonies of $50>$ cells were stained using $0.01 \%$ crystal violet stain and counted using an EVOS microscope (A, C). (B, D) Colony formation was measured as a percentage of an untreated DMSO vehicle control. Data denoted ${ }^{*}(p<0.05),{ }^{* *}(p<0.01)$ and $^{* * *}(\mathrm{p}<0.001)$ were significant compared to the untreated control analysed by one-way ANOVA with Dunnett's multiple comparison test. All data is representative of at least three independent experiments performed in triplicate and presented as mean \pm SEM.

(A)

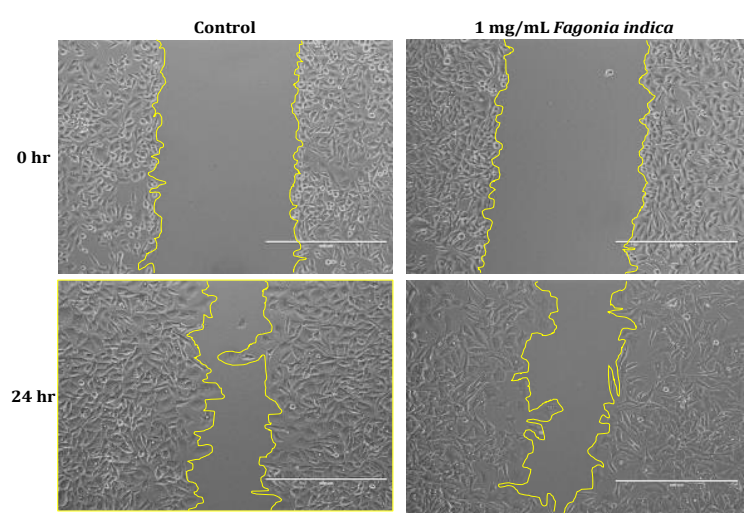

(B)

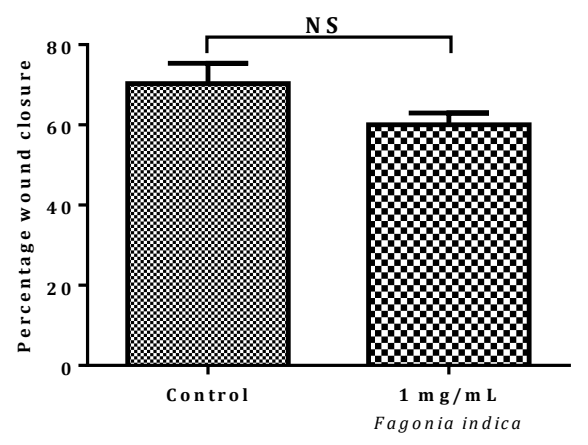

(C)

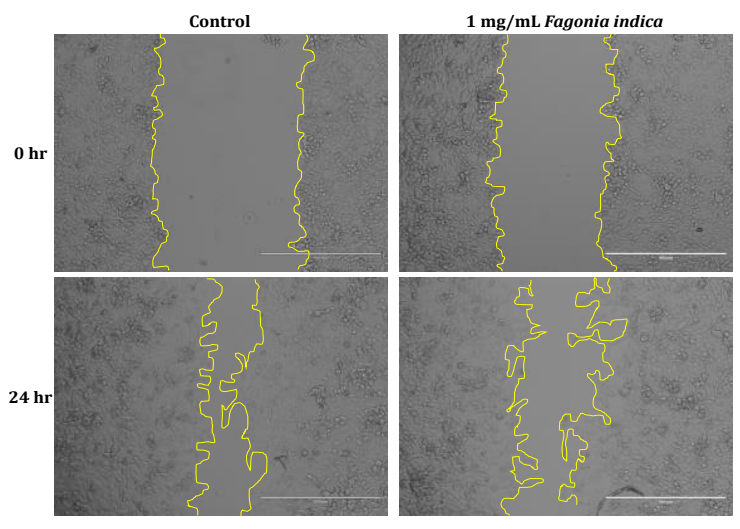

(D)

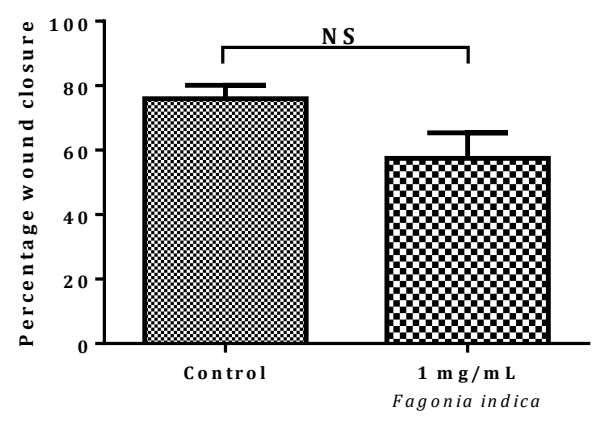

Figure 3: Fagonia indica treatment inhibits migration of colon cancer cell lines. (A) H630 and (C) RKO cell monolayers were scratched with a $20 \mu \mathrm{L}$ pipette tip and treated with $1 \mathrm{mg} / \mathrm{mL}$ of aqueous Fagonia indica for 24 hours. Wound closure was captured with an EVOS microscope at 0 hour and 24 hours timepoints at x 10 magnification. Wound closure was determined using ImageJ software and is displayed as percentage wound closure after 24 hours for H630 (B) and RKO cell lines (D). Data denoted NS were not significant compared to an untreated control analysed by unpaired students t test. All data is representative of at least three independent experiments performed in triplicate and presented as mean \pm SEM.

2.3 Fagonia indica effects $p 38 / M A P K$ signalling pathways and reduces expression of VEGF-A, NF- $\kappa B$ and ICAM-1

P38 mitogen activated protein kinase (MAPK) signalling is activated upon stress-stimuli from the environment and is associated with inhibition of cell cycle progression and induction of apoptosis. SB203580 is a selective inhibitor of p38 MAPK and was used to inhibit Fagonia indica 
activation of p38 signalling $(1.5 \mathrm{mg} / \mathrm{mL})$. Inhibition of p38 significantly alleviated loss in cell viability in $\mathrm{H} 630$ cells by $31.6 \%$ (Figure $4 \mathrm{~A}$ ) and by $31.4 \%$ in RKO cells (Figure $4 \mathrm{~B}$ ). When activated, p38 indirectly inhibits oncogene Akt. Upon activation, Akt acts as a mediator for the P13K/Akt kinase signalling pathway, leading to increased cellular metabolism and proliferation. Activating Akt signalling pathways with SC79, significantly alleviated the loss in cell viability in H630 cells by 35\% (Figure 4C), this was much lower in RKO cells at 15.3\% (Figure 4D).

(A)
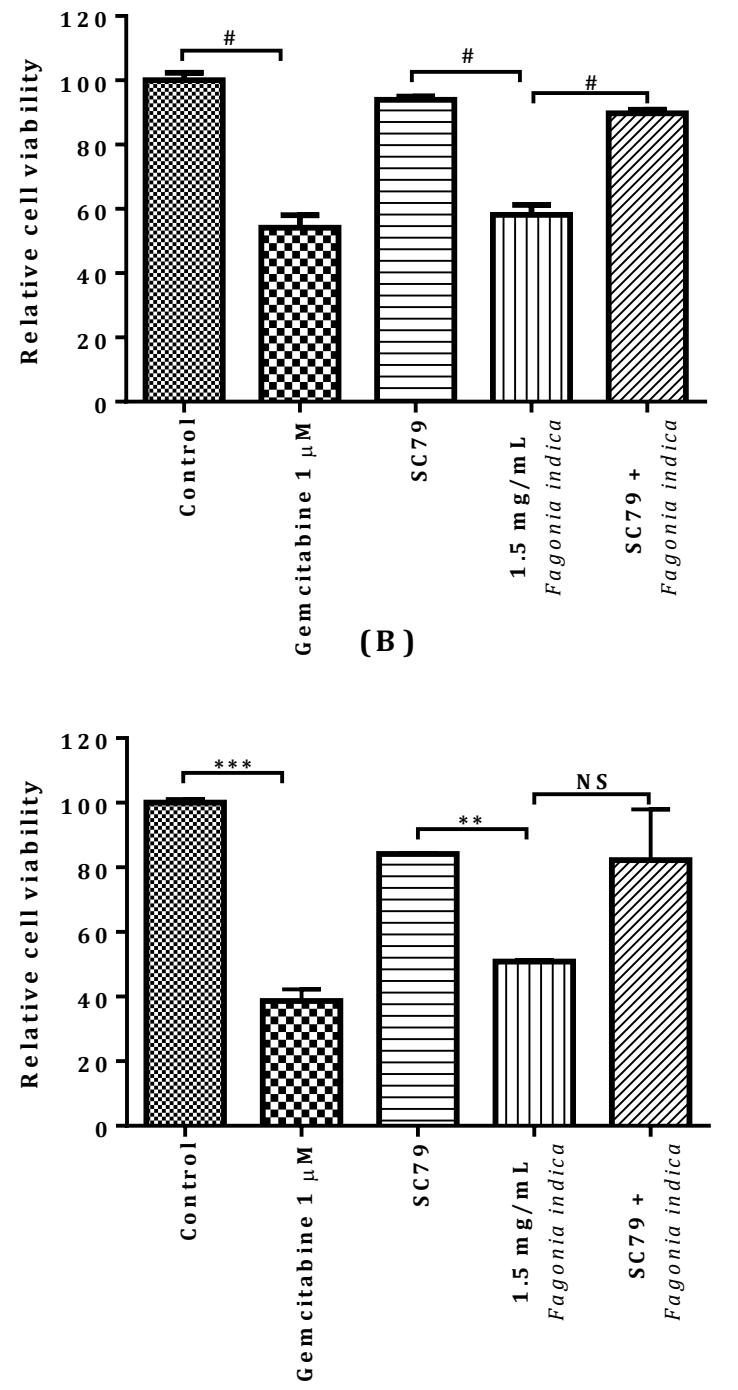

(C)
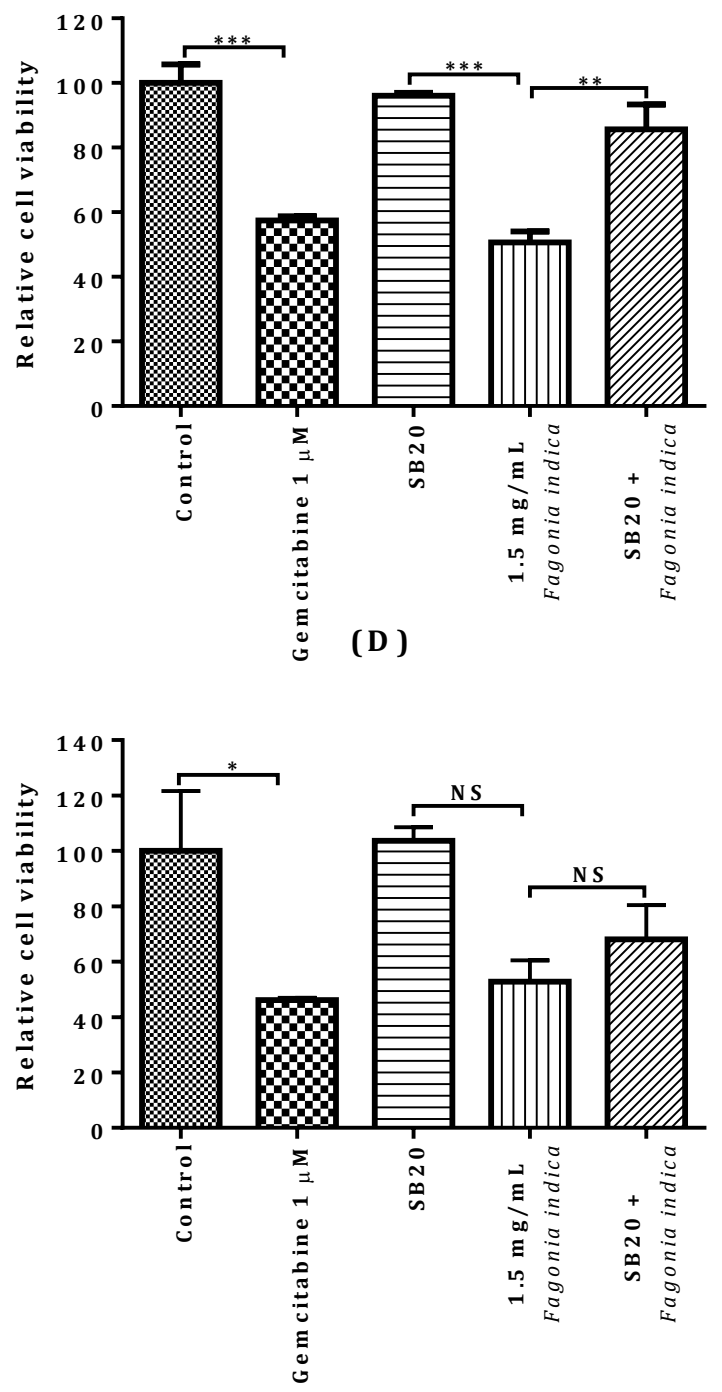

Figure 4: Effects of p38 MAP kinase inhibition and AKT activation on Fagonia indica induced colon cancer cytotoxicity. (A) H630 cells were treated with $1.5 \mathrm{mg} / \mathrm{mL}$ of aqueous extract and $10 \mu \mathrm{M}$ of SC79 Akt activator, or (C) 10 $\mu \mathrm{M}$ of p38 MAPK inhibitor SB203580 for 48 hours. (B) RKO cells were treated with $1.5 \mathrm{mg} / \mathrm{mL}$ of aqueous extract and $10 \mu \mathrm{M}$ of SC79 Akt activator, or (D) $10 \mu \mathrm{M}$ of p38 MAPK inhibitor SB203580 for 48 hours.1 $\mu \mathrm{M}$ Gemcitabine was used as a positive control. Cell viability was measured as a percentage of an untreated DMSO vehicle control using the MTT assay. Data denoted as ${ }^{*}(\mathrm{p}<0.05),{ }^{* *}(\mathrm{p}<0.01),{ }^{* * *}(\mathrm{p}<0.001)$ and $\#(\mathrm{p}<0.0001)$ were statistically significant compared to the untreated DMSO vehicle control, analysed using one-way ANOVA with Sidaks's multiple comparison test. Data 
denoted as NS was not significant. All data points are representative of three independent experiments, performed in triplicate and are expressed as mean \pm SEM.

Angiogenesis and inflammation are key hallmarks of cancer, and both are processes which have important roles in the development, initiation and advancement of cancer. Expression of vascular endothelial growth factor receptor A (VEGF-A) mRNA was measured in RKO and H630 colon cancer cell lines using RT-PCR (Figure 5). After 6 hours of treatment with Fagonia indica $(1 \mathrm{mg} / \mathrm{mL})$ relative gene expression of VEGF-A was significantly reduced in $\mathrm{H} 630$ cells to 0.26 , and in RKO cells to 0.51 (Figure 5A-B). After 24 hours, expression of VEGF-A stabilised to that of the control. Apatanib is a selective tyrosine kinase inhibitor of VEGF-R2. Inhibition of VEGF-R2 significantly alleviated the loss in Fagonia indica induced cellular viability by $8.1 \%$ and $19.6 \%$ in $\mathrm{H} 630$ and $\mathrm{RKO}$ cells, respectively (Figure $6 \mathrm{~A}, \mathrm{C}$ ). NF- $\kappa \mathrm{B}$ is a major transcription factor that upregulates several genes associated with inflammation and immune responses. Expression of NFk $\beta$ subunit; p65, was measured in both H630 and RKO colon cancer cells lines treated with Fagonia indica (1 $\mathrm{mg} / \mathrm{mL}$ ) at 6 and 24 hours via RT-PCR (Figure 5). Extract treatment significantly reduced relative gene expression in both $\mathrm{H} 630$ and RKO cells to 0.06 and 0.47 , respectively (Figure 5C-D). Expression of p65 remained significantly reduced after 24 hours. Caffeic acid phenethyl ester (CAPE) is a specific inhibitor of the nuclear transcription factor NF- $\kappa$ B. Inhibition of NF- $\kappa B$ did not significantly affect cytotoxicity of Fagonia indica in RKO and H630 colon cancer cells (Figure $6 \mathrm{~B}, \mathrm{D})$. Finally, expression of ICAM-1 was measured using RT-PCR. Relative gene expression was significantly reduced after 6 hours of treatment with Fagonia indica to 0.18 and 0.42 in H630 and RKO cells, respectively (Figure 6E-F). After 24 hours expression of ICAM-1 stabilised to that of the control in $\mathrm{H} 630$ cells, whereas expression dropped further to 0.19 in RKO cells.

(A)

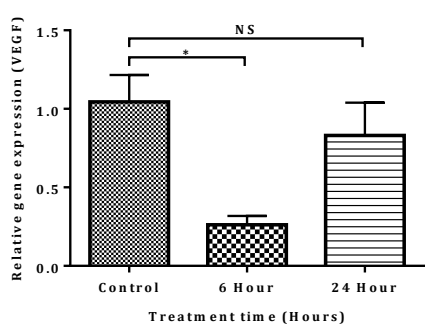

(B)

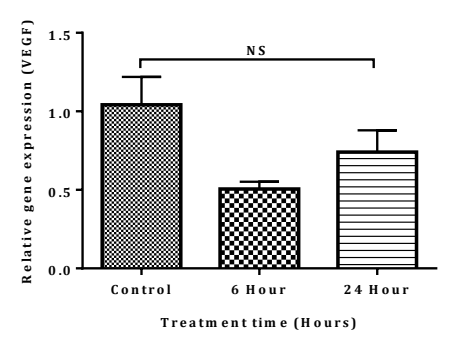

(C)

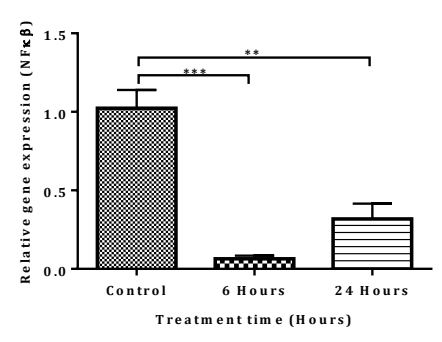

(D)

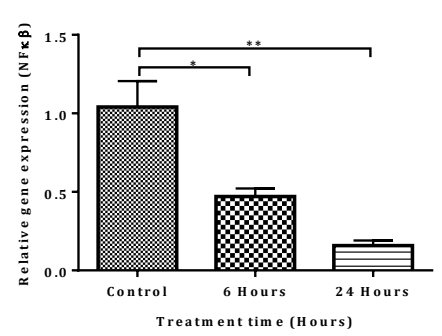

(E)

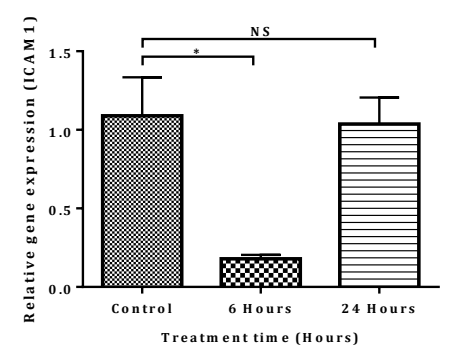

(F)

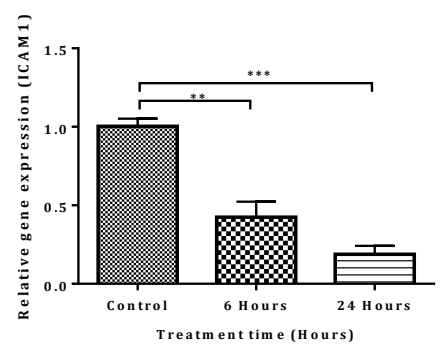

Figure 5: Fagonia indica extract treatment reduces expression of VEGF, NFผ $\beta$ and ICAM-1 in colon cancer cell lines. Gene expression of VEGF-A was determined on (A) H630 and (B) RKO colon cancer cells. Gene expression of NFк $\beta$ was determined on (C) H630 and (D) RKO colon cancer cells. Gene expression of ICAM-1 was determined on (E) H630 
and (F) RKO colon cancer cells. Pellets were collected and mRNA extracted after 6 and 24 hours of treatment with $1 \mathrm{mg} / \mathrm{mL}$ Fagonia indica. Values were normalised to housekeeping genes actin and YHWAZ and displayed as relative gene expression to an untreated control. Data denoted ${ }^{*}(p<0.05),{ }^{* *}(p<0.01),{ }^{* *}(p<0.001)$ and \# $(p<0.0001)$ were significant compared to the untreated control analysed by one-way ANOVA with Dunnett's multiple comparison test. Data denoted as NS were not significant $(\mathrm{p}>0.05)$ All data is representative of at least three independent experiments performed in triplicate and presented as mean \pm SEM.

(A)

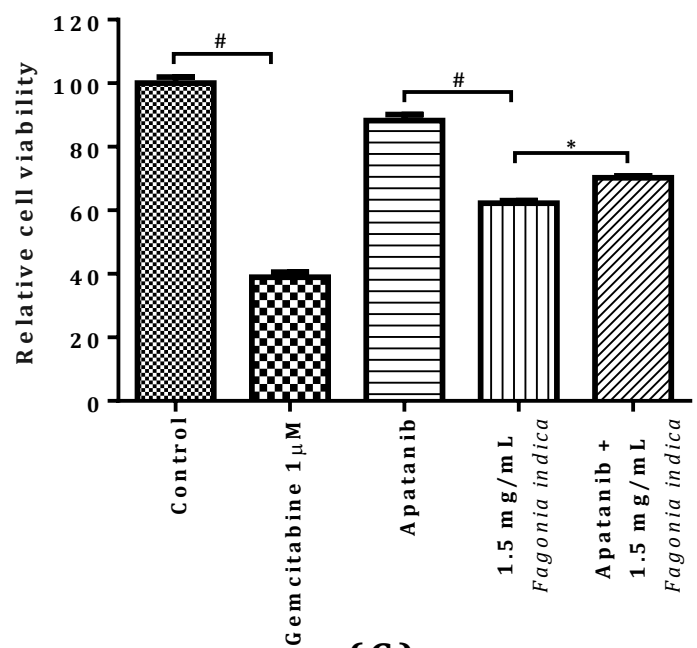

(C)

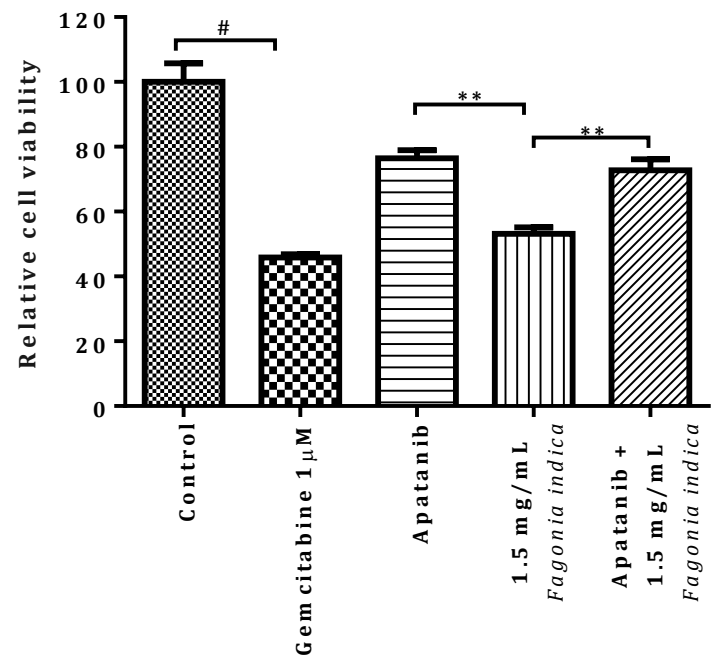

(B)
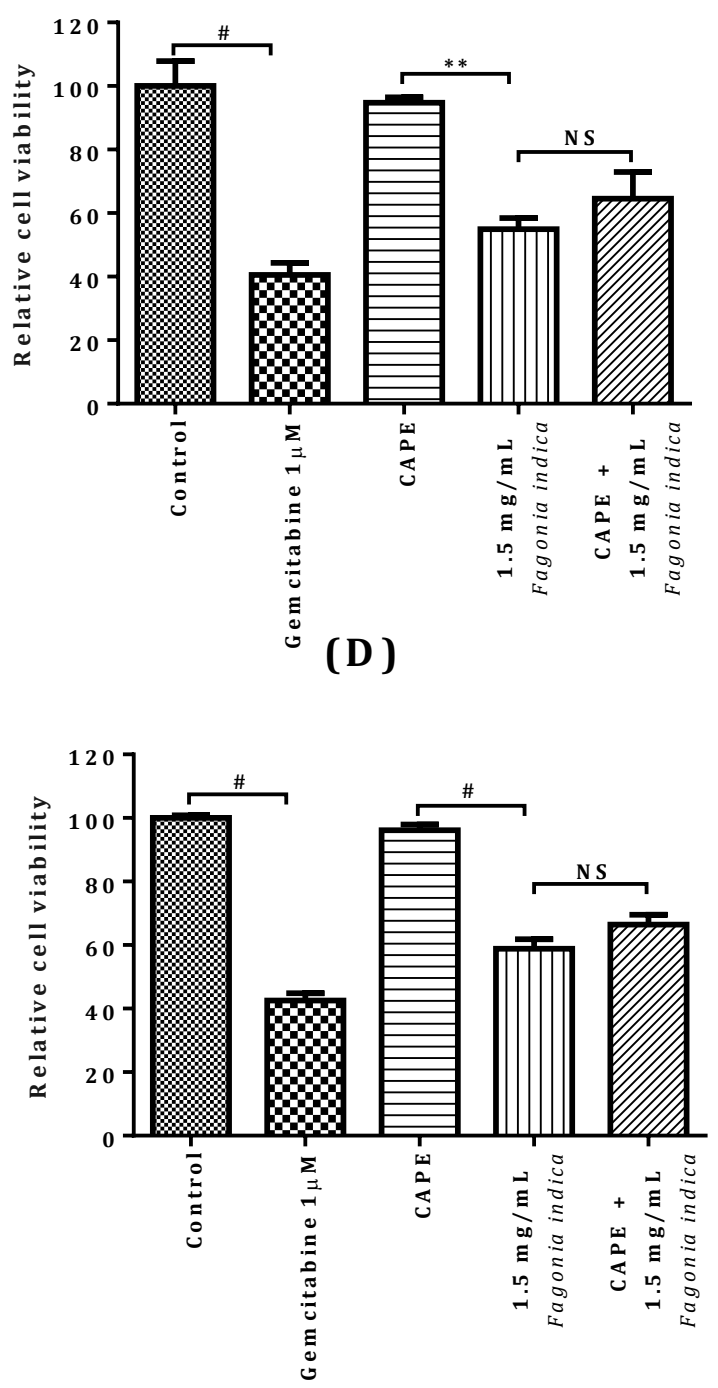

Figure 6: Effects of VEGF-A and NF- $\mathrm{KB}$ inhibition and on Fagonia indica induced colon cancer cytotoxicity. (A) $\mathrm{H} 630$ and (C) RKO colon cancer cells were treated with $1.5 \mathrm{mg} / \mathrm{mL}$ of aqueous extract and $1 \mu \mathrm{M}$ of VEGF-A inhibitor Apatanib for 48 hours. (B) H630 and (D) RKO colon cancer cells were treated with $1.5 \mathrm{mg} / \mathrm{mL}$ of aqueous extract and 1 $\mu \mathrm{M}$ of NF- $\kappa \mathrm{B}$ inhibitor CAPE for 48 hours. $1 \mu \mathrm{M}$ Gemcitabine was used as a positive control. Cell viability was measured as a percentage of an untreated DMSO vehicle control using the MTT assay. Data denoted as ${ }^{*}(\mathrm{p}<0.05),{ }^{* *}$ $(\mathrm{p}<0.01),{ }^{* *}(\mathrm{p}<0.001)$ and \# $(\mathrm{p}<0.0001)$ were statistically significant compared to the untreated DMSO vehicle control, analysed using one-way ANOVA with Sidaks's multiple comparison test. Data denoted as NS was not significant. All data points are representative of three independent experiments, performed in triplicate and are expressed as mean \pm SEM. 


\subsection{Fagonia indica reduces cell viability in chemotherapy resistant colon cancers}

Resistance to single chemotherapeutic agents occurs almost universally and drug tolerance in cancer is widely documented. Resistance of $\mathrm{H} 630$ and RKO cell lines was established in supplementary figure 1. Fagonia indica induced a time and concentration-dependent reduction in cell viability by $57.7 \%$ and $63.2 \%$ in tomudex resistant RKO (RKO-TDX) and gemcitabine resistant H630 (H630-GM) cell lines after $2.5 \mathrm{mg} / \mathrm{mL}$ of treatment for 72 hours. (Figure 7A-B) This was much lower in 5-fluorouracil resistant H630 (H630-5FU) cells, in which there was only a 34.3\% reduction in cell viability after 72 hours (Figure 7C). To determine the ability of Fagonia indica to re-sensitize resistant cell lines to chemotherapy, H630 and RKO resistant cell lines were pretreated with Fagonia indica for 24 hours. Pre-treatment of RKO-TDX resistant cells with Fagonia indica, reduced tomudex induced cell viability cells by $27.8 \%$ (Figure 7D). Similarly, pre-treatment of H630-GM cells reduced cell viability in gemcitabine treated cells by $33.7 \%$ (Figure 7E).

(A)

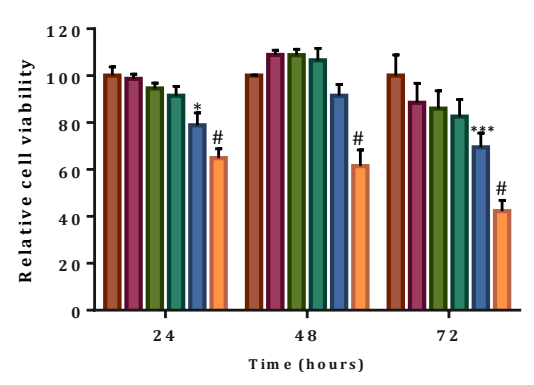

(B)

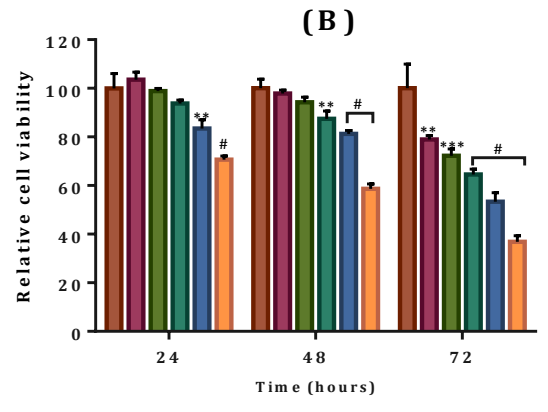

(C)

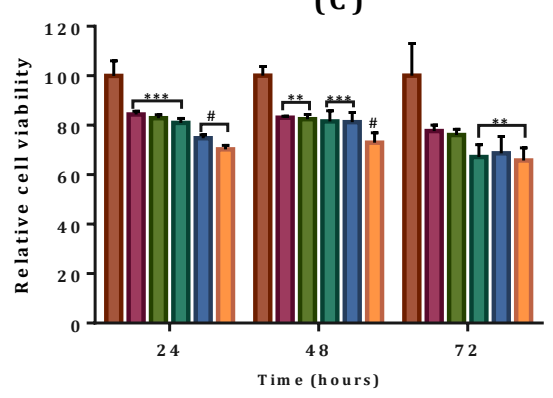

(D)
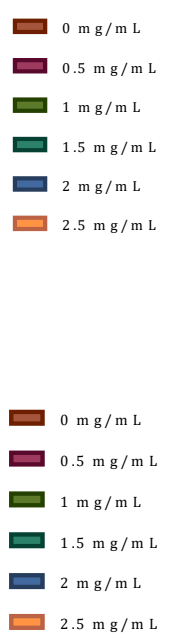

$2.5 \mathrm{mg} / \mathrm{m} \mathrm{L}$

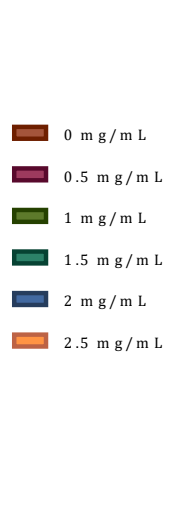

(E)

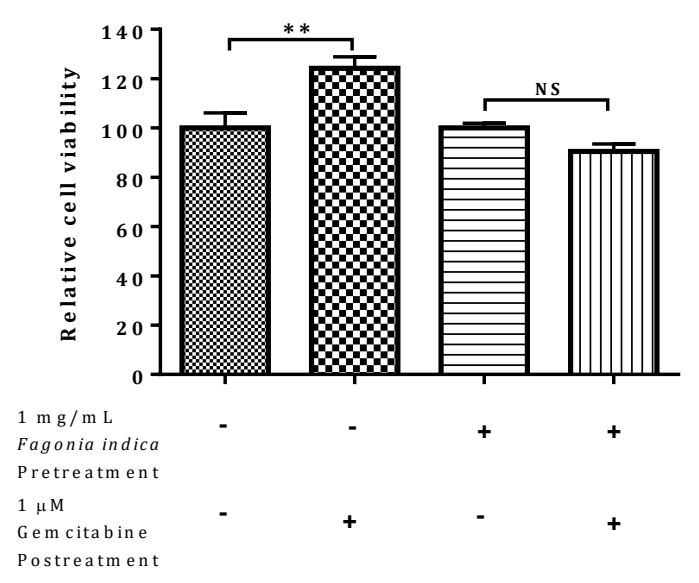

Figure 7: Fagonia indica extract treatment reduces in vitro cell viability of gemcitabine, 5-fluorouracil and tomudex resistant colon cancer cell lines. (A) Tomudex resistant $(2 \mu \mathrm{M}) \mathrm{RKO}$, (B) gemcitabine resistant $(1 \mu \mathrm{M}) \mathrm{H} 630$ (B) and 5- 
fluorouracil $(10 \mu \mathrm{M})$ resistant $\mathrm{H} 630$ cells were treated with $0-2.5 \mathrm{mg} / \mathrm{mL}$ Fagonia indica extract for 24-72 hours. Cell viability was determined as a percentage of an untreated DMSO vehicle control using MTT assay. (D) Tomudex resistant RKO and (E) gemcitabine resistant $\mathrm{H} 630$ cells were pre-treated with $1 \mathrm{mg} / \mathrm{mL}$ aqueous Fagonia indica extract for 24 hours prior to treatment with gemcitabine/ tomudex for 48 hours. Cell viability was determined as a percentage of relevant DMSO/ Fagonia indica vehicle control using MTT assay. Data denoted ${ }^{*}(\mathrm{p}<0.05),{ }^{* *}(\mathrm{p}<0.01),{ }^{* * *}(\mathrm{p}<0.001)$ and \# $(\mathrm{p}<0.0001)$ were significant compared to the untreated control analysed by one-way (D-E) and (A-C) two-way ANOVA with Dunnett's multiple comparison test. All data is representative of at least three independent experiments performed in triplicate and presented as mean \pm SEM.

\subsection{Fagonia indica reduces expression of $A B C$ transporters in chemotherapy resistant colon cancers.}

As overexpression of $\mathrm{ABC}$ transporters has been implicated in the acquisition of resistance phenotypes in several cancer types, therapeutic inhibitors of $A B C$ transporters have become of interest as a potential mechanism to reverse multidrug resistance. In the current study difference in mRNA expression of ABCC4 and ABCG2 genes were established between wild-type and chemotherapy resistant clones of H630 and RKO colon cancers (Figure 8). In H630 cells, both ABCG2 and ABCC4 were over-expressed in H630-GM resistant cells by 5.9 and 7.7 times of the H630-WT control (Figure 8A, E). ABCG2 and ABCC4 were also significantly overexpressed in H630-5FU resistant cells, by 5.7 and 12.4 times of the control (Figure 8E, G). Having established overexpression of ABCG2 and ABCC4 in H630-GM resistant cells, expression of resistant cell lines post treatment with Fagonia indica was determined. After 6 hours of Fagonia indica treatment, mRNA expression of ABCG2 and ABCC4 was significantly reduced to 0.32 and 0.24 , respectively. This reduction was maintained after 24 hours of treatment (Figure 8B, D). Similarly, Fagonia indica reduced expression of AGCG2 and ABCC4 in H630-5FU resistant cells to 0.24 and 0.18 of the untreated control after 6 hours. This reduction was maintained after 24 hours of treatment.

(A)

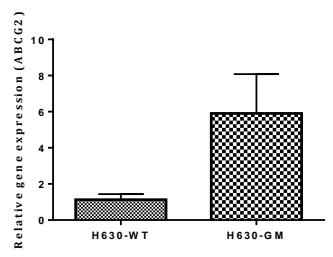

( E)

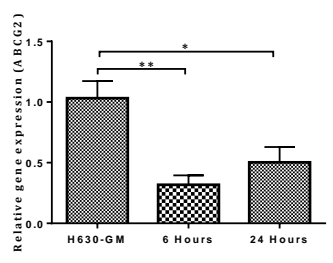

(B)

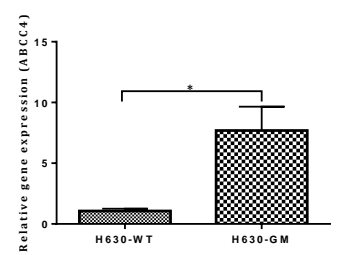

(F)

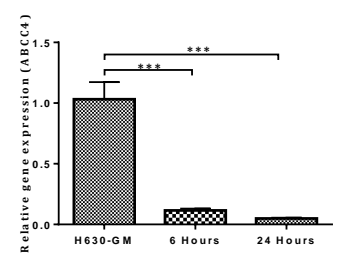

(C)

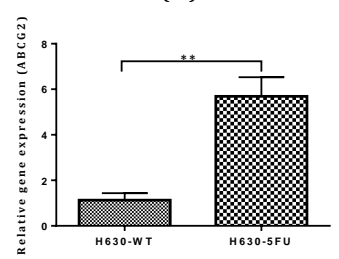

(G)

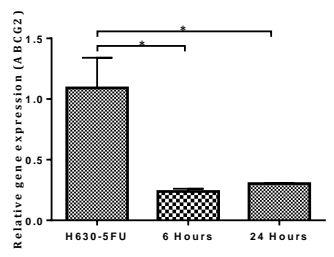

(D)

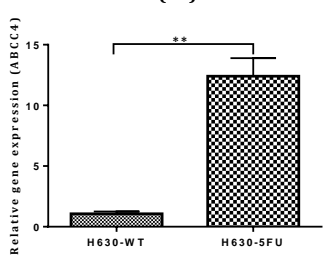

(

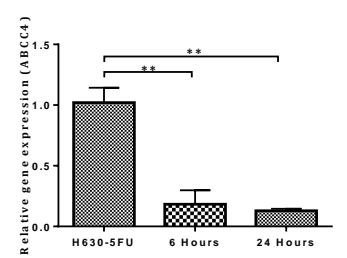

Figure 8: Fagonia indica extract treatment reduces expression of ABCC4 and ABCG2 in chemotherapy resistant $\mathrm{H} 630$ colon cancer. Gene expression of ABCG2 was determined on (A) wild-type H630 and gemcitabine resistant H630 clones, (C) wild-type H630 and 5-fluorouracil resistant H630 clones to determine resistance mechanisms. Gene expression of ABCG2 was also determined after treatment with 1mg/mL Fagonia indica for 6 and 24 hours, in gemcitabine resistant (B) and 5-fluorouracil resistant (D) H630 clones. Gene expression of ABCC4 was also determined on (E) wild-type H630 and gemcitabine resistant H630 clones, (G) wild-type H630 and 5-fluorouracil resistant H630 clones to determine resistance mechanisms. Gene expression of ABCC4 was also determined after treatment with $1 \mathrm{mg} / \mathrm{mL}$ Fagonia indica for 6 and 24 hours, in gemcitabine resistant (F) and 5-fluorouracil resistant $(\mathrm{H}) \mathrm{H} 630$ clones. 
Values were normalised to housekeeping genes actin and YHWAZ. Data was analysed using the inverse delta Ct method and displayed as relative to an untreated control. Data denoted ${ }^{*}(p<0.05),{ }^{* *}(p<0.01)$ and ${ }^{* * *}(p<0.001)$ were significant compared to a control analysed by one-way ANOVA with Dunnett's multiple comparison test. All data is representative of at least three independent experiments performed in triplicate and presented as mean \pm SEM.

Changes in mRNA expression in ABCG2 and ABCC4 between RKO-WT and RKO-TDX resistant cells was established. Interestingly, expression of ABCG2 was not significantly affected in RKOTDX cells, whereas ABCC4 expression was significantly increased to 3.85 times of the control (Figure 9A, C). After treatment with Fagonia indica for 24 hours, expression of ABCG2 was significantly increased in RKO-TDX cells to 3.31 times the untreated control (Figure 9B), whereas expression of ABCC4 was reduced at both 6- and 24-hours post treatment (Figure 9D).

(A)

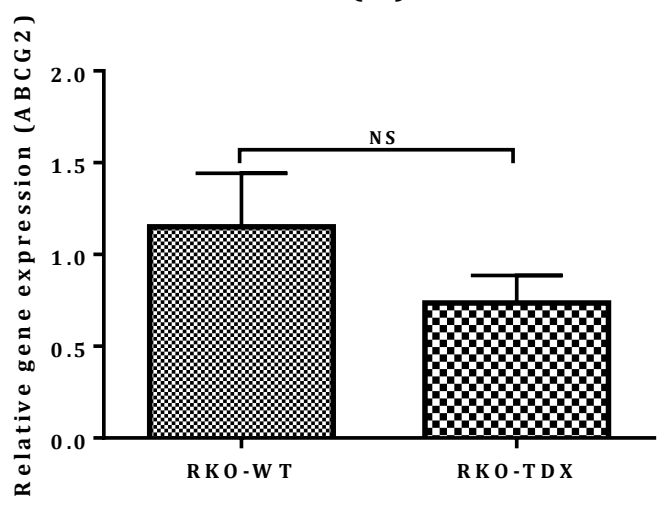

(C)

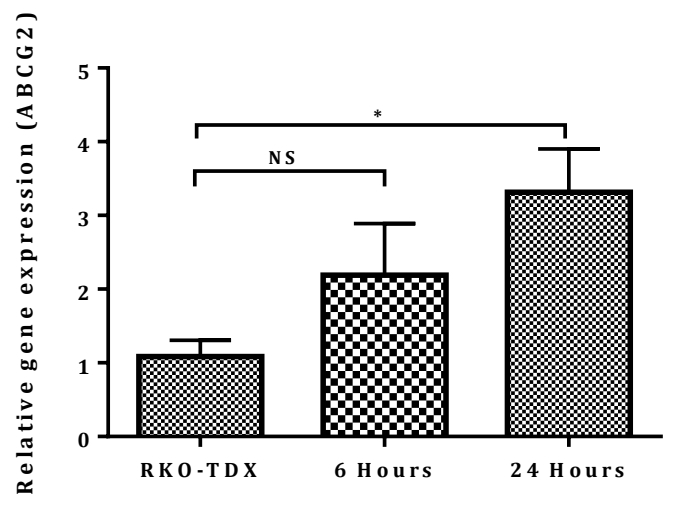

(B)

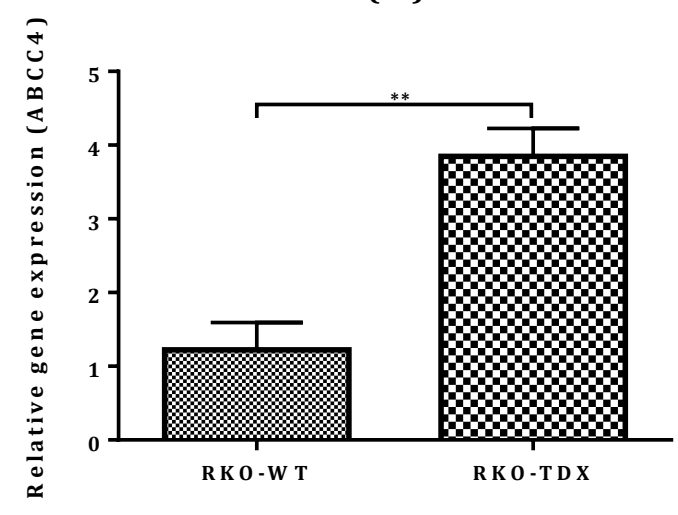

(D)

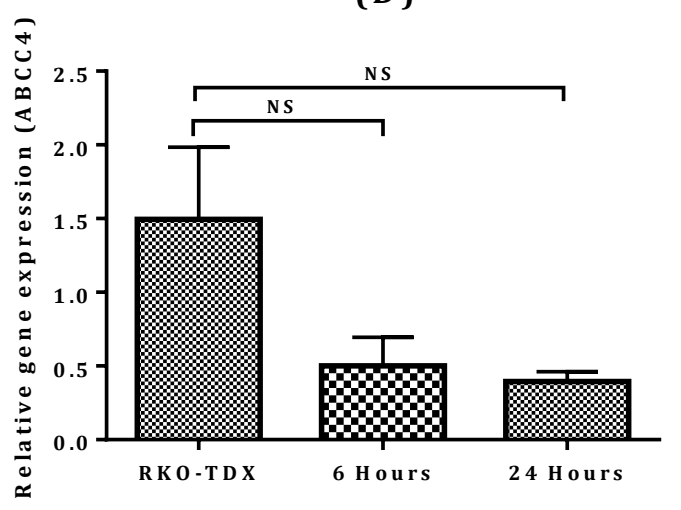

Figure 9: Fagonia indica extract treatment reduces expression of ABCC4 and ABCG2 in chemotherapy resistant RKO colon cancer. Gene expression of ABCG2 was determined on (A) wild-type RKO and tomudex resistant RKO clones. Gene expression of ABCG2 was also determined after treatment with $1 \mathrm{mg} / \mathrm{mL}$ Fagonia indica for 6 and 24 hours, in tomudex resistant RKO clones H630 (B). Gene expression of $\mathrm{ABCC} 4$ was determined on (C) wild-type RKO and tomudex resistant RKO clones. Gene expression of ABCC4 was also determined after treatment with 1mg/mL Fagonia indica for 6 and 24 hours, in tomudex resistant RKO clones H630 (D). Values were normalised to housekeeping genes actin and YHWAZ. Data was analysed using the inverse delta $\mathrm{Ct}$ method and displayed as relative to an untreated control. Data denoted $^{*}(\mathrm{p}<0.05),{ }^{* *}(\mathrm{p}<0.01)$ and ${ }^{* *}(\mathrm{p}<0.001)$ were significant compared to a control analysed by one- 
way ANOVA with Dunnett's multiple comparison test. All data is representative of at least three independent experiments performed in triplicate and presented as mean \pm SEM.

\section{Discussion}

Fagonia indica has been utilised for decades in folk medicine as a purgative and topical treatment for cancer [38]. Previous research determined that an aqueous extract of Fagonia indica was able to induce apoptosis in breast cancer cell lines, MCF7 and MDA-MB-231 [39]. In the current study, an aqueous extract of Fagonia indica displayed significant cytotoxic activity against both RKO and H630 colon cancer cell lines. No previous study has examined the effect of an aqueous extract of Fagonia indica against colon cancer cell lines. Other research has demonstrated that ethyl-acetate and butanol extractions of Fagonia indica were able to cause significant reductions in cell viability in HCT colon cancer cell line [35]. Previously, isolated triterpenes; Indicacin and Fagonicin, were extracted from an ethanolic extract and displayed up to $51.4 \%$ growth inhibition in H-29 colon cancer cells [38]. These findings are supplemented by the identification of a novel steroidal saponin glycoside from Fagonia indica which was cytotoxic against both breast and colon cancer cell lines [41]. Measuring intracellular ATP provides a reliable depiction of cellular metabolism, which also correlates to cellular viability [42]. In the current study, Fagonia indica treatment significantly reduced metabolic production of ATP. We also investigated the effect of Fagonia indica on the proliferation, clonogenic capacity and migration of colon cancer cells. Fagonia indica treatment significantly reduced the proliferative capacity of single cells over 7 days, indicating a pro-longed effect of treatment on the proliferation of colon cancer cell lines [42]. Previous studies have indicated a role of Akt activation and signalling in tumorigenic pathways, including evasion and migration [43-44]. Further research is required to determine the relationship between Fagonia indica treatment and Akt phosphorylation as a mechanism of action.

The p38-mitogen activated protein kinase (MAPK) signalling pathway is a pivotal feature in stress-induced fate decisions, such as cell cycle arrest and apoptosis [45-46]. P38 MAPK signalling pathways are activated in response to double strand DNA damage, leading to transcription of cell repair and apoptotic genes, such as p21 [47]. This pathway has been used successfully as a molecular target in the development of other chemotherapeutic agents such a paclitaxel and novel treatment MTBT [47-48]. Inhibiting p38 activation with competitive inhibitor SB203580 led to a significant reduction in extract-induced loss of cell viability in $\mathrm{H} 630$ cell lines. P38 activation can lead to downstream signalling which indirectly inhibits Akt. Akt is an established oncogene, which upon activation can promote tumorigenic cell behaviour common in colon cancer [49]. In the current study, Akt activation by SC79 confounded the cytotoxic effect of Fagonia indica in both cell lines. Other studies have demonstrated the potential of a Rosemary plant extract to inhibit the activation and phosphorylation of Akt in vitro [50]. It is possible that Akt is a target of Fagonia indica treatment, this provides a wider picture of p53 activation and extract induced apoptosis in Fagonia indica.

Vascular endothelial growth factor (VEGF), is a signal protein secreted by cells and associated largely with the formation of new vascularisation, tumour proliferation, growth and metastasis [51]. In a novel finding, we demonstrate a role for VEGF stimulation in Fagonia indica induced cellular cytotoxicity in human colon cancer cell lines. Treatment with aqueous Fagonia indica 
extract, led to a significant reduction in mRNA expression of VEGF-A in both RKO and H630 cancer cell lines. Inhibition of VEGF-A with Apatanib, partially abrogated the cytotoxic effects of Fagonia indica. VEGF plays a pivotal role in the signalling and up-regulation of target genes such as ICAM-1 via the phosphorylation of PI3K/Akt/NO pathways [24]. ICAM-1 has been associated with several tumour types due its ability to modulate inflammation and regulate vascular permeability. In the current study, ICAM-1 mRNA was reduced to a similar extent as VEGF expression in both cell lines. In RKO cancer cells, this reduced expression was enhanced at 24 hours, potentially indicating a more prominent role for ICAM-1 in this cell line. VEGF also induces adhesion molecules during inflammatory states, by stimulating expression of ICAM-1 and VCAM-1 in an NF- $\kappa$ B dependent manor [52-53]. In other research, inhibition of NF- $\kappa \mathrm{B}$ subunits; NF- $\mathrm{B} 2$ and RelA, resulted in a marked decrease in ICAM1 expression with a corresponding reduction in smooth muscle proliferation and Akt phosphorylation [54]. In the present study, expression of NF- $\kappa \mathrm{B}$ subunit p65 was reduced in both cell lines after treatment with Fagonia indica. However, inhibiting NF- $\kappa$ B activation using CAPE did not significantly affect cellular cytotoxicity, suggesting that NF- $\kappa \mathrm{B}$ signalling is not a key mechanism of Fagonia indica but may be a downstream or off-target effect of treatment.

ABCG2 and ABCC4 have been previously implicated in the acquisition of multi-drug resistance of colon cancer cells to chemotherapy, as such, inhibition of membrane transporters remains an effective mechanism of reversing resistance in these cell types [55-56]. In the present study, populations of colon cancer cells demonstrating resistance to chemotherapeutic agents tomudex, gemcitabine and 5-fluorouracil were isolated and expanded. Gemcitabine and 5-fluorouracil resistant H630 colon cancer cells had significantly increased mRNA expression of ABCG2 and ABCC4, compared to the wild-type control. Resistance to 5-fluourouracil is well documented in the literature and has been correlated previously with an over expression of ABCG2 [57]. Resistant H630 clones were treated with Fagonia indica extract, resulting in a significant reduction in both ABCC4 and ABCG2. Previous studies have demonstrated an ability of plant-derived molecules to inhibit ABCG2 [58]. Other studies found that plant extract of Evodia rutaecarpa suppressed ABCG2 mediated drug resistance in colon cancer cell lines, via the inhibition of NF$\kappa B$ signalling pathways [59]. Silencing ABCC4 transport has also been shown to be a successful method of drug reversal [60-61]. In RKO cell lines, only ABCC4 was overexpressed in tomudex resistant clones, with expression of ABCG2 increasing upon treatment with Fagonia indica. Treatment with Fagonia indica was also able to reduce the expression of ABCG2 in tomudex resistant RKO cells, following similar patterns to resistant H630 cell lines. It is important to establish in future work the mechanisms behind extract induced- loss in gene expression [61].

We have shown for the first time that an aqueous extract of Fagonia indica induces cell death and metabolic disruption in two phenotypically distinct colon cancer cell lines. There is a possibility that Fagonia indica treatment utilises Akt/MAPK signalling pathways. In addition, extract treatment reduces VEGF, ICAM-1 and NF- $\kappa$ B expression which may be attributed to angiogenic and inflammatory processes. Fagonia indica was also able to induce cell death in chemotherapy resistant colon cancer cell lines and this was associated with down-regulation of $\mathrm{ABC}$ transporters, ABCG2 and ABCC4. This provides a novel mechanism by which an aqueous extract of Fagonia indica; which is used frequently as a treatment in traditional Pakistani communities, 
can cause cytotoxicity in colon cancer cells. However, the molecular composition of the bioactive compounds of the Fagonia indica remains relatively unknown.

\section{Materials and Methods}

\section{Cell culture}

Wild-type (WT) and resistant RKO and H630 human colon cancer epithelial cells (produced by Professor W Wang, Wolverhampton University) were cultured in high glucose DMEM (Sigma, UK) with 2nM L-glutamine supplemented with 10\% FCS (Sigma, UK) and 1\% penicillin/streptomycin $(50 \mathrm{U} / \mathrm{ml})$ (Sigma, UK) and incubated at $37^{\circ} \mathrm{C}$ with $5 \% \mathrm{CO}_{2}$. Resistant clones were produced by repeated exposure of the drug in a dose-dependent manner, detailed in Table 1.

\begin{tabular}{|l|l|l|l|}
\hline Colon cancer cell lines & $\begin{array}{l}\text { Resistant } \\
\text { chemotherapy }\end{array}$ & $\begin{array}{l}\text { Resistant } \\
\text { concentration }\end{array}$ & $\begin{array}{l}\text { Chemotherapy } \\
\text { Manufacturer }\end{array}$ \\
\hline Cell line & Gemcitabine & $10 \mu \mathrm{M}$ & Santa Cruz Biotechnology \\
\hline H630-GM & 5-fluorouracil & $10 \mu \mathrm{M}$ & Sigma, UK \\
\hline H630-5FU & Tomudex & $2 \mu \mathrm{M}$ & Santa Cruz Biotechnology \\
\hline
\end{tabular}

Table 1. Conditions of drug resistant colon cancer cell lines.

\section{Fagonia indica preparation}

An aqueous extract of Fagonia indica was produced to replicate traditional methods of consumption, following a previous described protocol [39]. The extract was filtered with filter paper (Fisher Scientific), before being subjected to a liquid-liquid partition with $3 \times$ equal volumes of culture-grade hexane (Fisher). The aqueous phase was collected and freeze-dried under vacuum and stored at $4^{\circ} \mathrm{C}$.

\section{Cell viability - neutral red assay}

Cell viability was determined using the Neutral red colorimetric assay [62]. In brief, cells were seeded in flat-bottomed 96-well plates (Costar) at a density of $1 \times 10^{4}$ cells/per well and left to adhere overnight. Cells were treated with plant extract $(0-2.5 \mathrm{mg} / \mathrm{mL})$ or gemcitabine $(1 \mu \mathrm{M})$ for 24-72 hours, before addition of neutral red reagent $(40 \mu \mathrm{g} / \mathrm{mL})$ (Acros organics) and incubation for 2 hours. Neutral red was solubilised with neutral red de-staining solution (50\% ethanol, $49 \%$ $\mathrm{dH} 20$ and 1\% glacial acetic acid). Optical intensity was measured at an absorbance of $540 \mathrm{~nm}$ using a Thermoscientific Multiskan GO microplate reader.

\section{Cell viability - MTT assay}

Cell viability was determined using the MTT (3-(4,5-dimethylthiazol-2-yl)-2,5diphenyltetrazolium bromide) [63]. In brief, cells were seeded in a flat-bottomed 96-well plate 
(Costar) at a density of $1 \times 10^{4}$ cells/per well and left to adhere overnight. Cells were treated with inhibitor (Table 2), plant extract $(0-2.5 \mathrm{mg} / \mathrm{mL})$, or gemcitabine $(1-10 \mu \mathrm{M})$ for $24-72$ hours, prior to addition of $0.5 \mathrm{mg} / \mathrm{mL}$ MTT (Acros organics) and incubation for 2 hours. Cells were lysed and formazan product solubilised with $100 \mu \mathrm{L}$ DMSO. Optical density was measured at an absorbance of $570 \mathrm{~nm}$ using a Thermoscientific Multiskan GO microplate reader.

\begin{tabular}{|l|l|l|l|l|}
\hline Inhibitors/activators used in MTT assays \\
\hline $\begin{array}{l}\text { Inhibitor/ } \\
\text { Activator }\end{array}$ & Target & Concentration & Manufacturer & Reference \\
\hline Apatanib & VEG-FA & $1 \mu \mathrm{M}$ & Sigma & {$[64-65]$} \\
\hline SC-79 & Akt activator & $10 \mu \mathrm{M}$ & Tocris & {$[66]$} \\
\hline SB203580 & $\begin{array}{l}\text { Akt and p38 } \\
\text { MAP kinase }\end{array}$ & $10 \mu \mathrm{M}$ & Tocris & {$[67]$} \\
\hline $\begin{array}{l}\text { Caffeic acid } \\
\text { phenethyl ester } \\
\text { (CAPE) }\end{array}$ & NF-kB & $1 \mu \mathrm{M}$ & Tocris & {$[68]$} \\
\hline
\end{tabular}

Table 2. Inhibitors/ activators used in this study

\section{Luminescent ATP assay}

Intracellular ATP was measured using the Luminescent ATP Detection Assay Kit (ab113849), following the manufacturers protocol. In brief, cells were seeded into sterile white bottom 96-well plates (Thermo Scientific) at a density of $2 \times 10^{4}$ cells/ per well and left to adhere overnight. Cells were treated with $1 \mathrm{mg} / \mathrm{mL}$ plant extract or low-glucose DMEM for 24 hours and luminescence was measured on the Orion II luminescent microplate reader. Intracellular ATP levels were measured as a percentage of the control.

\section{Scratch wound assay}

Cellular migration of cells was assessed by wound scratch assay. Briefly, cells were seeded in 12well plates (Corning) at a density of $2 \times 10^{5}$ cells/per well and left to adhere serum-depleted overnight. Straight scratches were introduced into each monolayer using a sterile $20 \mu \mathrm{L}$ pipette tip, before washing with HBSS. Cells were treated with $1 \mathrm{mg} / \mathrm{mL}$ plant extract and antiproliferative drug $5 \mu \mathrm{g} / \mathrm{mL}$ mitomycin (Sigma, UK) for 24 hours. Images were taken on an EVOS microscope and wound closure was analysed with ImageJ software.

\section{Colony formation assay (CFA)}

The capacity for a single cell to proliferate was determined using a colony formation assay [69]. In brief, cells were treated for 24 hours with $2 \mathrm{mg} / \mathrm{mL}$ of Fagonia indica, $1 \mu \mathrm{M}$ gemcitabine positive control or DMSO vehicle control. Cells were seeded into 24 well plates at a density of 200-400 cells/mL and incubated for 7 days. The colonies were fixed with 100\% methanol (Fisher) for 20 mins before staining with $0.1 \%$ crystal violet solution (Sigma, UK). Visible colonies of $>50$ cells 
were counted manually using a transparent film and a Motic AE2000 light microscope (X4 magnification).

\section{RNA extraction and quantitative real-time PCR}

RNA was extracted using the Isolate RNA mini kit (Bioline), as per the manufacturer's instructions. To elute the isolated RNA sample, 30-80 $\mu \mathrm{L}$ of RNase-free water was added to the Spin Column membrane, before a final spin at $6000 \mathrm{x} g$ for $1 \mathrm{~min}$ into a $1.5 \mathrm{~mL}$ DNA elution tube (Sigma, UK). RNA concentration was measured using the NanoDrop ${ }^{\mathrm{TM}} 1000$ spectrophotometer and stored at $-80^{\circ} \mathrm{C}$. $500 \mathrm{ng}$ of RNA was reversed transcribed using the Precision nanoScript ${ }^{\mathrm{TM}} 2$ Reverse Transcription kit (Primerdesign), to produce cDNA. Samples were placed in a thermocycler under the following conditions: $20 \mathrm{~min}$ at $42{ }^{\circ} \mathrm{C}, 10 \mathrm{~min}$ at $75{ }^{\circ} \mathrm{C}$ and a hold temperature of $4{ }^{\circ} \mathrm{C}$, before finally being diluted $1: 10$ and stored at $-20^{\circ} \mathrm{C}$. Prior to PCR set up a 'master mix' was prepared containing $10 \mu \mathrm{L}$ of PrecisionPLUS 2x qPCR mastermix with SYBR green (Primerdesign), $3 \mu \mathrm{L}$ of RNase/DNase-free water and $1 \mu \mathrm{L}$ of both forward and reverse primers (Table 3). For each independent reaction, $5 \mu \mathrm{L}$ of cDNA and $15 \mu \mathrm{L}$ of master mix were added to each well in triplicate, $5 \mu \mathrm{L}$ of DNase-free water was used as a control. Gene expression levels were determined using the PikoReal ${ }^{\mathrm{TM}} 96$ (Thermo Scientific) and analysed using the PikoReal $^{\mathrm{TM}}$ Software 2.2. Conditions of the PikoReal ${ }^{\mathrm{TM}}$ thermal cycler were as follows, $10 \mathrm{~min}$ at $95{ }^{\circ} \mathrm{C}, 15 \mathrm{sec}$ at $95^{\circ} \mathrm{C}$ and $1 \mathrm{~min}$ at $60^{\circ} \mathrm{C}$ (40 cycles), and cooling of $40{ }^{\circ} \mathrm{C}$ for $10 \mathrm{sec}$. All PCR setup was conducted under sterile conditions using a PCR workstation (UVP).

\begin{tabular}{|c|c|c|}
\hline \multicolumn{3}{|c|}{ Primers used in qPCR } \\
\hline Gene (primers) & Manufacturer & Primer sequence \\
\hline Actin & Invitrogen & $\begin{array}{l}\text { F: CTGGAACGGTGAAGGTGACA } \\
\text { R: AAGGGACTTCCTGTAACAATGCA }\end{array}$ \\
\hline YWHAZ & Invitrogen & $\begin{array}{l}\text { F: CCGCCAGGACAAACCAGTAT } \\
\text { R: CCGCCAGGACAAACCAGTAT }\end{array}$ \\
\hline VEGF-A & Invitrogen & $\begin{array}{l}\text { F: CTACCTCCACCATGCCAAGT } \\
\text { R: GCAGTAGCTGCGCTGATAGA }\end{array}$ \\
\hline NFкB- P65 & Invitrogen & $\begin{array}{l}\text { F: CCTGCTTCTGTCTCTAGGAGGTA } \\
\text { R: TAAGCAGAAGCATTAACTTCTCTGGA }\end{array}$ \\
\hline ICAM-1 & Invitrogen & $\begin{array}{l}\text { F: GACTCCAATGTGCCAGGCTT } \\
\text { R: TAGGTGCCCTCAAGATCTCG }\end{array}$ \\
\hline ABCC4 & Invitrogen & $\begin{array}{l}\text { F: TGTGGCTTTGAACACAGCGTA } \\
\text { R: CCAGCACACTGAACGTGATAA }\end{array}$ \\
\hline ABCG2 & Invitrogen & $\begin{array}{l}\text { F: CAGGAGGCCTTGGGATACTT } \\
\text { R: TATAGAGGCCTGGGATT }\end{array}$ \\
\hline
\end{tabular}

Table 3. RT-PCR primer sequences used in this study.

\section{Statistics}

Statistical analysis of data was conducted using GraphPad Prism. For comparisons of two groups a student $t$ test was used. For comparisons of more than two groups with one independent 
variable, a one-way Anova with multiple comparisons was used and for two independent variables a two-way Anova was used with multiple comparisons. Sidak's and Dunnett's post-hoc tests were used for multiple comparisons. A value of $p<0.05$ was considered significant.

Supplementary Materials: Supplementary materials can be found at www.mdpi.com/xxx/s1.

Author Contributions: Conceptualisation, J.E.B., A.L and A.J.R.; Methodology, A.J.L., Validation, A.J.L.; Formal Analysis, J.E.B and A.J.L.; Investigation, A.J.L; Resources, A.J.R., J.E.B. and A.C., Writing - original draft, A.J.L, J.E.B and A.J.R.; Writing - review \& editing, A.J.L, J.E.B and A.J.R., Visualisation, A.J.L, J.E.B and A.J.R.; Supervision, J.E.B and A.J.R.; Funding acquisition, J.E.B and A.C.

Funding: Please add: "This research received no external funding" or "This research was funded by NAME OF FUNDER, grant number XXX" and "The APC was funded by XXX". Check carefully that the details given are accurate and use the standard spelling of funding agency names at https://search.crossref.org/funding, any errors may affect your future funding.

Acknowledgments: Many thanks to Kiran Shabir for help with the PikoReal software.

Conflicts of Interest: Declare conflicts of interest or state "The authors declare no conflict of interest." Authors must identify and declare any personal circumstances or interest that may be perceived as inappropriately influencing the representation or interpretation of reported research results. Any role of the funders in the design of the study; in the collection, analyses or interpretation of data; in the writing of the manuscript, or in the decision to publish the results must be declared in this section. If there is no role, please state "The funders had no role in the design of the study; in the collection, analyses, or interpretation of data; in the writing of the manuscript, or in the decision to publish the results".

\section{Abbreviations}

\begin{tabular}{ll} 
- & ABC \\
- & Akt \\
- & ATP \\
- & ABCC4 2 \\
- & ANOVA \\
- & BMI \\
- & CAPE \\
- & DMSO \\
- & H630-WT \\
- & H630-GM \\
- & $\mathrm{H} 630-5 F U$ \\
- & $\mathrm{ICAM}-1$ \\
- & $\mathrm{MAPK}$ \\
- & $\mathrm{MCF}-7$ \\
- & $\mathrm{MTT}$ \\
- & $\mathrm{mRNA}$ \\
- & $\mathrm{NF}-\mathrm{kB}$ \\
- & $\mathrm{NR}$ \\
- & $\mathrm{PCR}$ \\
- & $\mathrm{RKO}-\mathrm{WT}$ \\
- & $\mathrm{RKO}-\mathrm{TDX}$ \\
- & $\mathrm{RT}-\mathrm{qPCR}$ \\
- & $\mathrm{SEM}$ \\
\hline
\end{tabular}

- $\quad$ ATP Binding Cassette

- Protein kinase B

- Adenosine triphosphate

- $\mathrm{ABC} C$ subfamily member $4 /$ Multidrug resistance protein 4

- $\mathrm{ABC}$ G subfamily member $2 /$ Breast cancer resistance protein

- Analysis of variance

- Body mass index

- Caffeic acid phenethyl acid

- Dimethyl sulfoxide

- Wild type H630 cells

- Gemcitabine resistant H630 cells

- 5-fluorouracil resistant H630 cells

- Intracellular adhesion molecule 1

- Mitogen activated protein kinase

- Michigan cancer foundation 7 cell line

- 3-(4,5-dimethylthiazol-2-yl)-2,5-diphenyltetrazolium bromide

- messenger RNA

- Nuclear factor kappa beta

- Neutral red

- Polymerase chain reaction

- Wild type RKO cells

- Tomudex resistant RKO cells

- Reverse transcription quantitative PCR

- Standard error of the mean 


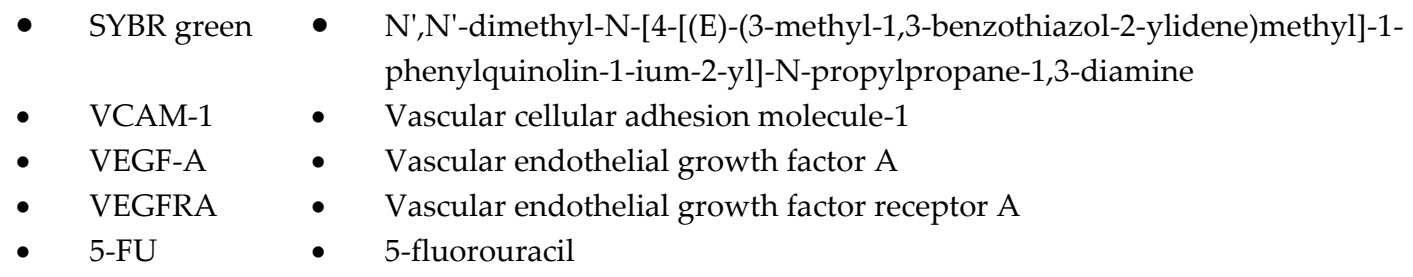

\section{Appendix A}

(A)

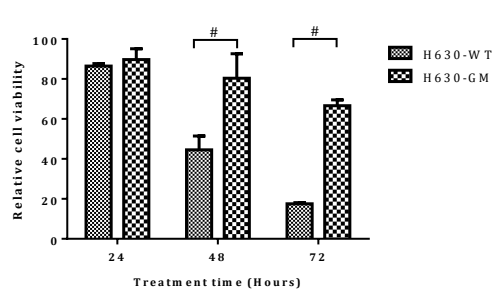

(B)

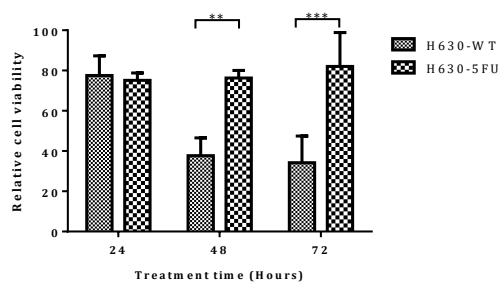

(C)

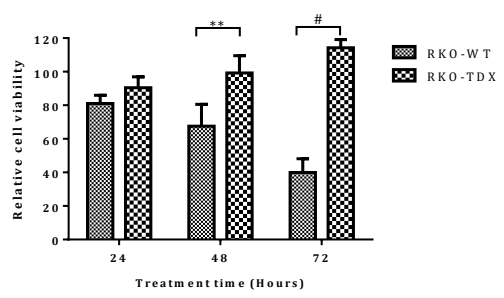

Supplementary Figure 1: Treatment of wild-type and chemotherapy resistant colon cancer cells with gemcitabine, 5-fluorouracil and gemcitabine. (A) H630-GM and H630-WT cells were treated with $1 \mu \mathrm{M}$ gemcitabine, (B) H630-5FU and H630-WT cells were treated with $10 \mu \mathrm{M}$ 5-fluorouracil and (C) RKO-TDX and RKO-WT cells were treated with $2 \mu \mathrm{M}$ for 24-72 hours. Cell viability was determined as a percentage of an untreated DMSO vehicle control using MTT assay. Data denoted $* *(p<0.01)$, *** $(\mathrm{p}<0.001)$ and $\#(\mathrm{p}<0.0001)$ were significant compared to the untreated control analysed by two-way ANOVA with Dunnett's multiple comparison test. All data is representative of at least three independent experiments performed in triplicate and presented as mean $\pm \mathrm{SD}$

\section{References}

1. Ferlay, J., Colombet, M., Soerjomataram, I., Dyba, T., Randi, G., Bettio, M., ... Bray, F. (2018). Cancer incidence and mortality patterns in Europe: Estimates for 40 countries and 25 major cancers in 2018. European Journal of Cancer, 103, 356-387

2. Arnold, M., Sierra, M. S., Laversanne, M., Soerjomataram, I., Jemal, A., \& Bray, F. (2017). Global patterns and trends in colorectal cancer incidence and mortality. Gut, 66(4), 683-691.

3. Araghi, M., Soerjomataram, I., Bardot, A., Ferlay, J., Cabasag, C. J., Morrison, D. S., ... Arnold, M. (2019). Changes in colorectal cancer incidence in seven high-income countries: a population-based study. The Lancet Gastroenterology and Hepatology, 4(7), 511-518.

4. Shaukat, A., Dostal, A., Menk, J., \& Church, T. R. (2017). BMI Is a Risk Factor for Colorectal Cancer Mortality. Digestive Diseases and Sciences, 62(9), 2511-2517.

5. Saliba, W., Rennert, H. S., Gronich, N., Gruber, S. B., \& Rennert, G. (2019). Red meat and processed meat intake and risk of colorectal cancer: A population-based case-control study. European Journal of Cancer Prevention, 28(4), 287-293.

6. Shen, L., Li, C., Li, N., Shen, L., \& Li, Z. (2020). Abnormal bowel movement frequency increases the risk of rectal cancer: Evidence from cohort studies with one million people. Bioscience Reports, 40(4), BSR20200355. 
7. Benninghoff, A. D., Hintze, K. J., Monsanto, S. P., Rodriguez, D. M., Hunter, A. H., Phatak, S., ... Ward, R. E. (2020). Consumption of the total western diet promotes colitis and inflammation-associated colorectal cancer in mice. Nutrients, 12(2), 544.

8. Torre, L. A., Siegel, R. L., Ward, E. M., \& Jemal, A. (2016). Global cancer incidence and mortality rates and trends - An update. Cancer Epidemiology Biomarkers and Prevention, 25, 16-27.

9. Xie, Y. H., Chen, Y. X., \& Fang, J. Y. (2020). Comprehensive review of targeted therapy for colorectal cancer. Signal Transduction and Targeted Therapy, 5, 22.

10. , T., Li, Z., Gao, C. Y., \& Cho, C. H. (2016). Mechanisms of drug resistance in colon cancer and its therapeutic strategies. World Journal of Gastroenterology, 22, 6876-6889.

11. Dagogo-Jack, I., \& Shaw, A. T. (2018). Tumour heterogeneity and resistance to cancer therapies. Nature Reviews Clinical Oncology, 15, 81-94.

12. Zaborsky, N., Gassner, F. J., Höpner, J. P., Schubert, M., Hebenstreit, D., Stark, R., ... Egle, A. (2019). Exome sequencing of the TCL1 mouse model for CLL reveals genetic heterogeneity and dynamics during disease development. Leukemia, 33(4), 957-968.

13. Gajdács, M., Spengler, G., Sanmartín, C., Marć, M. A., Handzlik, J., \& Domínguez-Álvarez, E. (2017). Selenoesters and selenoanhydrides as novel multidrug resistance reversing agents: A confirmation study in a colon cancer MDR cell line. Bioorganic and Medicinal Chemistry Letters, 27(4), 797-802.

14. Tsukamoto, M., Sato, S., Satake, K., Miyake, M., \& Nakagawa, H. (2017). Quantitative evaluation of drug resistance profile of cells expressing wild-type or genetic polymorphic variants of the human ABC transporter ABCC4. International Journal of Molecular Sciences, 18(7), 1435.

15. Tan, K. W., Sampson, A., Osa-Andrews, B., \& Iram, S. H. (2018). Calcitriol and calcipotriol modulate transport activity of ABC transporters and exhibit selective cytotoxicity in MRP1-overexpressing cells. Drug Metabolism and Disposition, 46(12), 1856-1866.

16. Meng, F., Zou, L., Zhang, T., Jiang, L., Ding, Y., Yu, P., \& Peng, J. (2018). Using LC-MS/MS-based targeted proteomics to monitor the pattern of $\mathrm{ABC}$ transporters expression in the development of drug resistance. Cancer Management and Research, 10, 2859-2870.

17. Drenberg, C., Hu, S., Li, L., Buelow, D., Orwick, S., Gibson, A., ... Baker, S. (2016). ABCC4 Is a Determinant of Cytarabine-Induced Cytotoxicity and Myelosuppression. Clinical and Translational Science, 9(1), 51-59.

18. Calcagno, A. M., Fostel, J. M., To, K. K. W., Salcido, C. D., Martin, S. E., Chewning, K. J., ... Ambudkar, S. V. (2008). Single-step doxorubicin-selected cancer cells overexpress the ABCG2 drug transporter through epigenetic changes. British Journal of Cancer, 98(9), 1515-1524.

19. Xie, Z.-Y., Lv, K., Xiong, Y., \& Guo, W.-H. (2014). ABCG2-Meditated Multidrug Resistance and Tumor-Initiating Capacity of Side Population Cells from Colon Cancer. Oncology Research and Treatment, 37(11), 666-672.

20. Gradilone, A., Pulcinelli, F., Lotti, L., Trifiro, E., Martino, S., Gandini, O., .. Gazzaniga, P. (2008). Celecoxib Upregulates Multidrug Resistance Proteins in Colon Cancer: Lack of Synergy with Standard Chemotherapy. Current Cancer Drug Targets, 8(5), 414-420. 
21. Chen, Q., Meng, F., Wang, L., Mao, Y., Zhou, H., Hua, D., .. Wang, W. (2017). A polymorphism in ABCC4 is related to efficacy of 5-FU/capecitabine-based chemotherapy in colorectal cancer patients. Scientific Reports, 7(1), 1-7.

22. Kochel, T. J., Reader, J. C., Ma, X., Kundu, N., \& Fulton, A. M. (2017). Multiple drug resistanceassociated protein (MRP4) exports prostaglandin E2 (PGE2) and contributes to metastasis in basal/ triple negative breast cancer. Oncotarget, 8(4), 6540-6554.

23. Nishida, N., Yano, H., Nishida, T., Kamura, T., \& Kojiro, M. (2006). Angiogenesis in cancer. Vascular Health and Risk Management, 2, 213-219.

24. Radisavljevic, Z., Avraham, H., \& Avraham, S. (2000). Vascular endothelial growth factor up-regulates

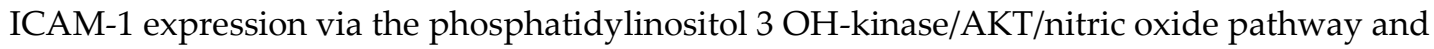
modulates migration of brain microvascular endothelial cells. Journal of Biological Chemistry, 275(27), 20770-20774.

25. Yeh, C. C., Shih, L. J., Chang, J. L., Tsuei, Y. W., Wu, C. C., Hsiao, C. W., .. Kao, Y. H. (2019). Synchronous vascular endothelial growth factor protein profiles in both tissue and serum identify metastasis and poor survival in colorectal cancer. Scientific Reports, 9(1), 1-12.

26. Dymicka-Piekarska, V., Guzinska-Ustymowicz, K., Kuklinski, A., \& Kemona, H. (2012). Prognostic significance of adhesion molecules (sICAM-1, sVCAM-1) and VEGF in colorectal cancer patients. Thrombosis Research, 129(4), e47-50.

27. Scaldaferri, F., Vetrano, S., Sans, M., Arena, V., Straface, G., Stigliano, E., ... Danese, S. (2009). VEGF-A Links Angiogenesis and Inflammation in Inflammatory Bowel Disease Pathogenesis.

Gastroenterology, 136(2), 585-595.

28. Manjunath, B. . (1956). The Wealth of India, Council of Scientific and Industrial Research, New Dehli, 4 : 01.

29. Beier, B. A. (2001). Two new unifoliolate species of Fagonia (Zygophyllaceae) from the Horn of Africa region, and the resurrection of F. subinermis from Iran. Nordic Journal of Botany, 21(5), 449-455.

30. Ali, S. S., Kasoju, N., Luthra, A., Singh, A., Sharanabasava, H., Sahu, A., \& Bora, U. (2008). Indian medicinal herbs as sources of antioxidants. Food Research International, 41, 1-15.

31. Ullah, S., Rashid Khan, M., Ali Shah, N., Afzal Shah, S., Majid, M., \& Asad Farooq, M. (2014). Ethnomedicinal plant use value in the Lakki Marwat District of Pakistan. Journal of Ethnopharmacology, 158(A), 412-422.

32. Adnan, M., Ullah, I., Tariq, A., Murad, W., Azizullah, A., Khan, A. L., \& Ali, N. (2014). Ethnomedicine use in the war affected region of northwest Pakistan. Journal of Ethnobiology and Ethnomedicine, 10, 16.

33. Ahmed, N., Mahmood, A., Tahir, S. S., Bano, A., Naseem Malik, R., Hassan, S., \& Ashraf, A. (2014). Ethnomedicinal knowledge and relative importance of indigenous medicinal plants of Cholistan desert, Punjab Province, Pakistan. Journal of Ethnopharmacology, 155(2):1263-1275.

34. Kadhim, B., Rasool, A., Shehab, N. G., Khan, S. A., \& Bayoumi, F. A. (2014). A new natural gel of Fagonia indica Burm f. extract for the treatment of burn on rats. Pakistan jouranl of Pharmecuetical Science, 27(1), 73-81.

35. Shehab, Naglaa Gamil, Abu-Gharbieh, E., \& Bayoumi, F. A. (2015). Impact of phenolic composition on 
hepatoprotective and antioxidant effects of four desert medicinal plants. BMC Complementary and Alternative Medicine, 15, 401.

36. Rahman, L., Shinwari, Z. K., Iqrar, I., Rahman, L., \& Tanveer, F. (2017). An assessment on the role of endophytic microbes in the therapeutic potential of Fagonia indica. Annals of Clinical Microbiology and Antimicrobials, 16(1), 53.

37. Soomro, A. L., \& Jafarey, N. A. (2003). Effect of Fagonia indica on experimentally produced Tumours in Rats. Journal of the Pakistan Medical Association, 53(6), 224-225.

38. Shehab, Naglaa G., Mahdy, A., Khan, S. A., Noureddin, S. M., \& Abd-Elhady, H. K. (2011). Chemical Constituents and Biological Activities of Fagonia indica Burm F. Research Journal of Medicinal Plant, 5(5), 531-546.

39. Lam, M., Carmichael, A. R., \& Griffiths, H. R. (2012). An Aqueous Extract of Fagonia cretica Induces DNA Damage, Cell Cycle Arrest and Apoptosis in Breast Cancer Cells via FOXO3a and p53 Expression. PLoS ONE, 7(6), e40152.

40. Tenbaum, S. P., Ordóñez-Morán, P., Puig, I., Chicote, I., Arqués, O., Landolfi, S., ... Palmer, H. G. (2012). $\beta$-Catenin confers resistance to PI3K and AKT inhibitors and subverts FOXO3a to promote metastasis in colon cancer. Nature Medicine, 18(6), 892-901.

41. Waheed, A., Barker, J., Barton, S. J., Owen, C. P., Ahmed, S., \& Carew, M. A. (2012). A novel steroidal saponin glycoside from Fagonia indica induces cell-selective apoptosis or necrosis in cancer cells. European Journal of Pharmaceutical Sciences, 47(2), 464-473.

42. Karakaş, D., Ari, F., \& Ulukaya, E. (2017). The MTT viability assay yields strikingly false-positive viabilities although the cells are killed by some plant extracts. Turkish Journal of Biology, 41(6), 919925.

43. Coronel-Hernández, J., López-Urrutia, E., Contreras-Romero, C., Delgado-Waldo, I., FigueroaGonzález, G., Campos-Parra, A. D., ... Pérez-Plasencia, C. (2019). Cell migration and proliferation are regulated by miR-26a in colorectal cancer via the PTEN-AKT axis. Cancer Cell International, 19(1).

44. Tang, F.-Y., Su, Y.-C., Chen, N.-C., Hsieh, H.-S., \& Chen, K.-S. (2008). Resveratrol inhibits migration and invasion of human breast-cancer cells. Molecular Nutrition \& Food Research, 52(6), 683-691.

45. Cuenda, A., \& Rousseau, S. (2007). p38 MAP-Kinases pathway regulation, function and role in human diseases. Biochimica et Biophysica Acta - Molecular Cell Research, 1773, 1358-1375.

46. Thornton, T. M., \& Rincon, M. (2009). Non-classical p38 map kinase functions: Cell cycle checkpoints and survival. International Journal of Biological Sciences, 5, 44-52.

47. Li, Y., Zhang, X., Zhang, J., Li, Y., Liu, W., Wang, Z., ... Si, S. (2014). A small molecule, MTBT, prevents cancer cell growth by activating p38 MAPK. Anti-Cancer Drugs, 25(4), 423-432.

48. Seidman, R., Gitelman, I., Sagi, O., Horwitz, S. B., \& Wolfson, M. (2001). The role of ERK 1/2 and p38 MAP-kinase pathways in Taxol-induced apoptosis in human ovarian carcinoma cells. Experimental Cell Research, 268(1), 84-92.

49. Wang, Y. K., Zhu, Y. L., Qiu, F. M., Zhang, T., Chen, Z. G., Zheng, S., \& Huang, J. (2010). Activation of Akt and MAPK pathways enhances the tumorigenicity of CD133+ primary colon cancer cells. Carcinogenesis, 31(8), 1376-1380. 
50. Jaglanian, A., \& Tsiani, E. (2020). Rosemary extract inhibits proliferation, survival, akt, and mTOR signaling in triple-negative breast cancer cells. International Journal of Molecular Sciences, 21(3), 810.

51. Lin, Y., Zhai, E., Liao, B., Xu, L., Zhang, X., Peng, S., ... Chen, M. (2017). Autocrine VEGF signaling promotes cell proliferation through a PLC-dependent pathway and modulates Apatinib treatment efficacy in gastric cancer. Oncotarget, 8(7), 11990-12002.

52. Kim, I., Moon, S. O., Kim, S. H., Kim, H. J., Koh, Y. S., \& Koh, G. Y. (2001). Vascular Endothelial Growth Factor Expression of Intercellular Adhesion Molecule 1 (ICAM-1), Vascular Cell Adhesion Molecule 1 (VCAM-1), and E-selectin through Nuclear Factor- $\kappa B$ Activation in Endothelial Cells. Journal of Biological Chemistry, 276(10), 7614-7620.

53. Bui, T. M., Wiesolek, H. L., \& Sumagin, R. (2020). ICAM-1: A master regulator of cellular responses in inflammation, injury resolution, and tumorigenesis. Journal of Leukocyte Biology, 108(3), 787-799.

54. Patel, H., Zaghloul, N., Lin, K., Liu, S. F., Miller, E. J., \& Ahmed, M. (2017). Hypoxia-induced activation of specific members of the NF-kB family and its relevance to pulmonary vascular remodeling. International Journal of Biochemistry and Cell Biology, 92, 141-147.

55. Hsu, H. H., Chen, M. C., Baskaran, R., Lin, Y. M., Day, C. H., Lin, Y. J., ... Huang, C. Y. (2018). Oxaliplatin resistance in colorectal cancer cells is mediated via activation of ABCG2 to alleviate ER stress induced apoptosis. Journal of Cellular Physiology, 233(7), 5458-5467.

56. Hu, J., Li, J., Yue, X., Wang, J. cang, Wang, J. feng, Liu, J. zhong, \& Kong, D. lu. (2017). Targeting BCRP/ABCG2 by RNA interference enhances the chemotherapy sensitivity of human colon cancer side population cells. Journal of Huazhong University of Science and Technology - Medical Science, 37(2), 231-236.

57. Qu, J. miao, You, J., Liu, H. guang, Huang, Q. di, \& Guo, G. long. (2013). Effect of 5-fluorouracil on the expression of ATP-binding cassette superfamily G member 2 in human colon cancer cell SW480. Chinese Journal of Gastrointestinal Surgery, 16(1), 89-92.

58. Holland, M. L., Lau, D. T. T., Allen, J. D., \& Arnold, J. C. (2007). The multidrug transporter ABCG2 (BCRP) is inhibited by plant-derived cannabinoids. British Journal of Pharmacology, 152(5), 815-824.

59. Sui, H., Zhou, L.-H., Zhang, Y.-L., Huang, J.-P., Liu, X., Ji, Q., .. Li, Q. (2016). Evodiamine Suppresses ABCG2 Mediated Drug Resistance by Inhibiting p50/p65 NF-кB Pathway in Colorectal Cancer. Journal of Cellular Biochemistry, 117(6), 1471-1481.

60. Zhang, Y. H., Wu, Q., Xiao, X. Y., Li, D. W., \& Wang, X. P. (2010). Silencing MRP4 by small interfering RNA reverses acquired DDP resistance of gastric cancer cell. Cancer Letters, 291(1), 76-82.

61. Wink, M., Ashour, M. L., \& El-Readi, M. Z. (2012). Secondary metabolites from plants inhibiting ABC transporters and reversing resistance of cancer cells and microbes to cytotoxic and antimicrobial agents. Frontiers in Microbiology, 3, 130.

62. Repetto, G., del Peso, A., \& Zurita, J. L. (2008). Neutral red uptake assay for the estimation of cell viability/ cytotoxicity. Nature Protocols, 3(7), 1125-1131.

63. Mosmann, T. (1983). Rapid colorimetric assay for cellular growth and survival: Application to proliferation and cytotoxicity assays. Journal of Immunological Methods, 65(1-2), 55-63. 
64. Kim, K. L., \& Suh, W. (2017). Apatinib, an inhibitor of vascular endothelial growth factor receptor 2, suppresses pathologic ocular neovascularization in mice. Investigative Ophthalmology and Visual Science, 58(9), 3592-3599.

65. Lin, A. B., McNeely, S. C., \& Beckmann, R. P. (2017). Achieving precision death with cell-cycle inhibitors that target DNA replication and repair. Clinical Cancer Research, 23, 3232-3240.

66. Yu, J., Luo, Y., \& Wen, Q. (2019). Nalbuphine suppresses breast cancer stem-like properties and epithelial-mesenchymal transition via the AKT-NFкB signaling pathway. Journal of Experimental \& Clinical Cancer Research, 38(1), 197.

67. Han, X., Chen, H., Zhou, J., Steed, H., Postovit, L. M., \& Fu, Y. (2018). Pharmacological inhibition of p38 MAPK by SB203580 increases resistance to carboplatin in A2780cp cells and promotes growth in primary ovarian cancer cells. International Journal of Molecular Sciences, 19(8), 2184.

68. Chuu, C. P., Lin, H. P., Ciaccio, M. F., Kokontis, J. M., Hause, R. J., Hiipakka, R. A., .. Jones, R. B. (2012). Caffeic acid phenethyl ester suppresses the proliferation of human prostate cancer cells through inhibition of p70S6K and Akt signaling networks. Cancer Prevention Research, 5(5), 788-797.

69. Crowley, L. C., Christensen, M. E., \& Waterhouse, N. J. (2016). Measuring survival of adherent cells with the Colony-forming assay. Cold Spring Harbor Protocols, 2016(8), 721-724.

(C) 2020 by the authors. Submitted for possible open access publication under the terms and conditions of the Creative Commons Attribution (CC BY) license (http://creativecommons.org/licenses/by/4.0/). 